\title{
?1
}

TI 2020-051/VIII

Tinbergen Institute Discussion Paper

\section{Business models for interoperable mobility services}

\section{Revision: April 2021}

Vincent A.C. van den Berg ${ }^{1}$

Henk Meurs ${ }^{2}$

Erik T. Verhoef ${ }^{1}$

${ }^{1}$ Vrije Universiteit Amsterdam

2 Radboud University 
Tinbergen Institute is the graduate school and research institute in economics of Erasmus University Rotterdam, the University of Amsterdam and Vrije Universiteit Amsterdam.

Contact: discussionpapers@tinbergen.nl

More TI discussion papers can be downloaded at https://www.tinbergen.nl

Tinbergen Institute has two locations:

Tinbergen Institute Amsterdam

Gustav Mahlerplein 117

1082 MS Amsterdam

The Netherlands

Tel.: +31(0)205984580

Tinbergen Institute Rotterdam

Burg. Oudlaan 50

3062 PA Rotterdam

The Netherlands

Tel.: +31(0)10408 8900 


\title{
Business models for interoperable mobility services
}

\author{
Vincent A.C. van den Berg, Vrije Universiteit Amsterdam \& Tinbergen Institute, v.a.c.vanden.berg@ vu.nl * \\ Henk Meurs, Radboud University \& MuConsult, h.meurs@fm.ru.nl \\ Erik T. Verhoef, Vrije Universiteit Amsterdam \& Tinbergen Institute, e.t.verhoef@vu.nl \\ ${ }^{*}$ Corresponding author. Address: Vrije Universiteit Amsterdam De Boelelaan 1105, 1081 HV Amsterdam
}

Date: Friday, 02 April 2021 


\begin{abstract}
Travellers often combine transport services from different firms to form trip chains: e.g. first taking a train and then a bus. Integration of different forms of public and private transport into a single service is gaining attention with the concept of mobility as a service (MaaS). Usually the attention focuses on such things as ease of use for travellers, and shifting demand away from the car. We focus on the effects of MaaS on behaviour and welfare via the market structure of transportation. In particular, we analyse three archetypical ways in which MaaS could be operationalised: Integrator, Platform, and Intermediary.

We find that these models differ strongly in how consumers and firms are affected by the availability of MaaS technologies. The Integrator model seems best for consumers and social welfare. It always leads to lower prices than free competition without MaaS and therefore benefits consumers; transport firm profits can be lower or higher. The Platform model tends to lead to an outcome that is relatively close to free competition without MaaS: prices can be higher or lower, while transport firm profits are lower. Finally, the Intermediary model tends to lead to much higher prices. Regulation of the price that the MaaS firm has to pay may lower prices, but, compared to the Integrator model, the change due to regulation is often small. So, even without price regulation, MaaS supply can already benefit consumers by increasing competition and removing serial marginalisation, even before we consider other benefits of MaaS such as information provision, ease of use, and a demand shift towards public transport.
\end{abstract}

JEL codes: D21, D43, R40

Key words: MaaS, market structure, platform, intermediary, integrator, regulation 


\section{Introduction}

Travellers often combine complementary transport services to form trip chains: e.g. using a taxi as the egress mode after a train trip. Parts of the trip chain are supplied either by individual firms or by vertically integrated firms. Vertical integration refers to the combination of individual services by a single supplier, jointly forming a trip chain from the origin to the destination. Travellers like such combined services as it makes their lives easier. In recent years, integration of various public and private transport services from different firms into a single service has gained increasing attention in the concept of mobility as a service (MaaS). Such integration can now be done in a user-friendly way via an app or website. ${ }^{1}$ It is expected that this will bring significant social, economic and environmental benefits, including greater accessibility, enhanced inclusion and less pollution (Jittrapirom et al., 2017). For the users, MaaS offers added value as they can simply use a single service, with a single payment channel, instead of multiple payment operations. ${ }^{2}$

We study how different ways of organising MaaS changes its effects on prices, profits, consumer surplus and welfare. Our main methodological contribution is the development of a consistent economic framework to study how different ways of organising MaaS determines its effects on prices, profits, consumer surplus and welfare. Our model builds on earlier studies, originating from the seminal studie by Economides and Salop (1992), and extends these by allowing for three archetypes of MaaS operators: the System Integrator, the Platform, and the Intermediary (see Section 2 for details and examples of these settings). We also analyse the effects of price regulation.

We consider a stylised setting with a four-link network, two competing transport providers, one MaaS service provider and assuming away any other effects of MaaS other than via the resulting market structure. The MaaS provider sells multimodal services from each of the two transport providers. We formulate a number of non-cooperative games with different pricing strategies by the players, as well as different power structures. Many papers have looked at how MaaS could be organised or modelled in more complicated and more detailed settings than our stylised setting, but in such settings it is impossible to gain insight on how the way MaaS is organised affects the market outcome, and attaining such an understanding is our goal. Similarly, adding other effects of MaaS would make the model more realistic but would muddle the effects of the market structure, making it difficult to attain insight.

From a welfare perspective, the provision by a single firm may reduce the distortive vertical negative externality that arises when multiple firms in a trip chain each apply their own markups. That externality would lead to customers facing multiple markups, leading to a combined price that is (even) higher than if a single monopoly firm were to control the entire trip. Such "serial marginalisation" also

\footnotetext{
${ }^{1} \mathrm{MaaS}$ is defined as a user-centric mobility distribution model in which all mobility services are aggregated by an operator and supplied to users through a single digital platform (Jittrapirom et al., 2017; Kamargianni et al., 2016; Pantelidis et al., 2020; Polydoropoulou et al., 2020). The platform can be realised by public or private agencies. In some cases, the platform is owned by a major transport firm: for instance, Transdev and Toyota, who have shares in the Finnish MaaS provider MaaS Global (Pöllänen, 2020).

${ }^{2}$ MaaS also brings many other benefits for users such as services for planning of trips.
} 
lowers the aggregate profits of the transport firms by leading to prices that are even higher than under a profit-maximising monopoly. However, there may also be a downside to the integration of transport services within a single firm: for alternative trip options such as parallel routes it may limit competition and then lead to higher prices rather than lower ones. The issue of competition vs integration/coordination has been important in the economics of transport services, as well as in other network industries (e.g. Economides and Salop, 1992). Competition is important for decreasing costs and prices and improving quality. Coordination is vital to ease travellers' lives, but it may also lead to socially suboptimal prices. In recent decades, integration of transport services within a single firm or by alliances of firms has received considerable attention (Brueckner, 2001; Meurs et al., 2020; Van de Velde et al., 2005; Verhoef, 2008; Vij et al., 2020).

The introduction of MaaS, often acting as an intermediary between the providers of transport services, raises many issues with respect to economic consequences for current transport service providers, as well as for travellers. What are the effects of the introduction of a MaaS service on the demand for transport and on the fares that users pay? What are the effects on pricing and profits of the transport providers? What prices can the MaaS provider charge? Will society be better off with the provision of MaaS integrating independent services, or with a single integrated firm offering all transport, or with independent transport providers without any integration via MaaS? This also relates to the large social concerns on the market power of large Internet and platform firms in general.

Although policymakers, researchers and consultants are spending much effort in addressing these issues, in transport an economic framework for addressing them is lacking. In this paper, we aim to develop such a framework and apply it to the issues mentioned above. For this purpose, we adopt the approach developed by Economides and Salop (1992) and examine a variety of alternative market structures. This approach has also been applied in analysing public transport networks, airlines, logistics, roads, etc. (e.g. Clark et al., 2014; D’Alfonso et al., 2016; Lin, 2004; Mantin, 2012; Park and Keh, 2003; Silva and Verhoef, 2013; van den Berg, 2013; Verhoef, 2008; Zhang et al., 2012). To the best of our knowledge, application of this framework for MaaS is new. ${ }^{3}$

The paper is structured as follows. In the next section, we formulate the supply chain structures and the associated models. In Section 3 the results will be shown for the key models. Section 4 presents

\footnotetext{
${ }^{3}$ Pandey et al. (2019) look at cooperation and competition between MaaS/ridesharing operators but in terms of supplying rides without considering pricing. Related papers looking at pricing of innovative transport technologies include Kaspi et al. (2014), Ke et al. (2020) and Ma and Zhang (2017) on ride sharing, Tan et al. (2019) on parking space sharing, Simoni et al. (2019) and van den Berg and Verhoef (2016) on autonomous vehicles, and Verhoef et al. (1996) on information provision. Di and Ban (2020) look at MaaS and congestion in more extensive networks than ours but do not look at pricing. Polydoropoulou et al. (2020) explore prototype business models for MaaS and how different actors may interact.

Recent papers have looked at pricing of MaaS in less stylised settings than ours but did not consider how different ways of organising the MaaS can alter the outcome. For instance, Djavadian and Chow (2017) used agent-based modelling while considering both the behaviour of consumers, transport firms and the MasS supplier. Expanding on Rasulkhani and Chow (2019), Pantelidis, et al. (2020) analysed MaaS traffic assignment in a large-scale network using a stable matching model.
} 
a numerical example and some sensitivity analysis. In Section 5 we reflect on possible price regulation. Section 6 presents the conclusions.

\section{Modelling supply chain structures for mobility services}

\subsection{The supply chain structures}

The setting for our analysis is illustrated in Fig. 1. Let there be two types of transport services, Mode 1 and 2, such as public transport and bike-sharing services. Each service supports two links (components) required to travel from the origin to the destination. $A$ denotes the upstream segment, and $B$ the downstream segment. Travellers can use four combinations $A_{i}$ and $B_{j}(\mathrm{i}, \mathrm{j}=1,2)$. Hence, the service components $A_{1}$ versus $A_{2}$ and $B_{1}$ versus $B_{2}$ are substitutes; conversely, $A_{1}$ and $B_{2}$ are complements and $A_{2}$ and $B_{1}$ are complements as well. We assume that all travellers are making trips from the single origin to the single destination and have to use a complete bundle using one segment $A$ and one segment $B$, so no individual segments are made (no partial trips). We consider two cases presented in Fig. 1: one with and one without a platform provider. The left panel represents the case of two independent firms that compete for individual trips. In the right-hand panel a MaaS-provider is added, which provides the two multimodal services shown as diagonals in the diagram. Hence, we focus on the stylised, symmetric case where each trip has two segments and each segment can be travelled via one of two modes. ${ }^{4}$ So the MaaS provider saves people the hassle of buying two segments and instead they can buy one full trip from the MaaS provider. Naturally, when staying within a mode and company-i.e. using $A_{l}$ and $B_{1}$ or $A_{2}$ and $B_{2}$-one also needs to buy only the combined trip. We assume that the key proposition of MaaS is to sell multimodal trips. The situation with the two independent firms without MaaS will serve as a reference situation for the analysis.

(a) Independent vertically integrated firms

(b) MaaS with independent

vertically integrated firms

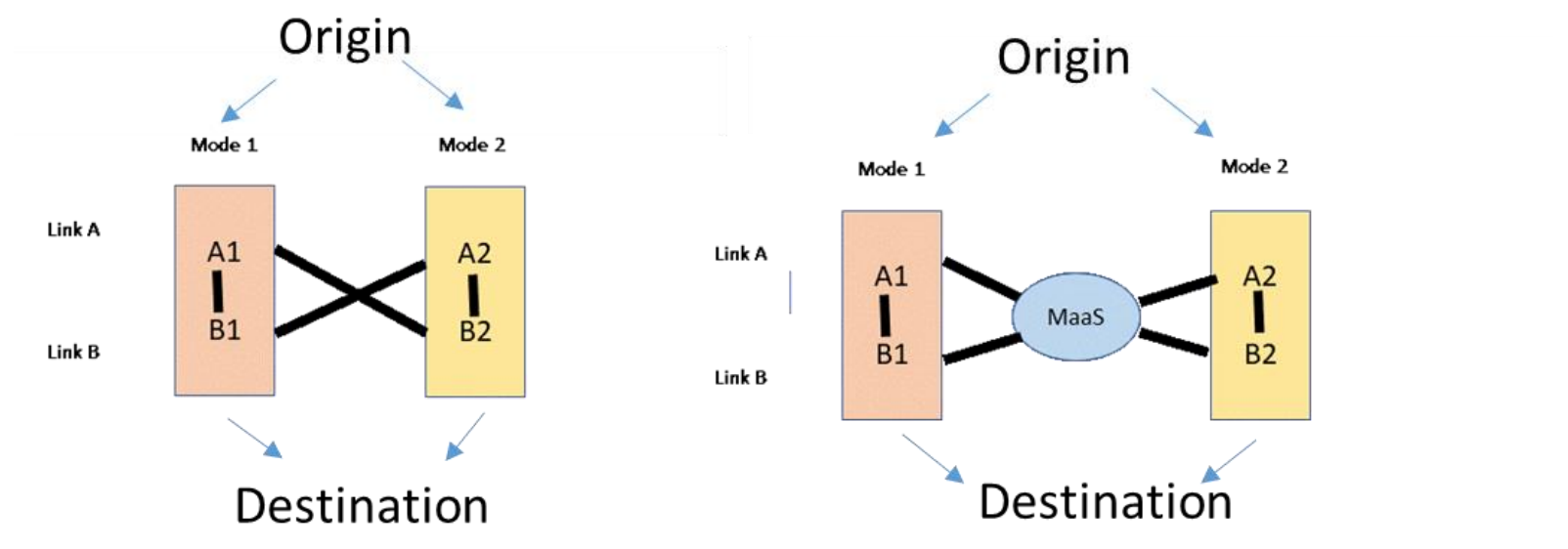

\footnotetext{
${ }^{4}$ In reality, some trips may have only one mode, but then MaaS is not that relevant. There may also be many more possible modes and segments, and then our setting may be seen as a stylised representation.
} 
Fig. 1: Combining mobility services (with and without MaaS) with two transport providers

The price of using firm $i$ for the first link $A$ is $p_{i}$, and for using $i$ for the second link $B$ it is $q_{i}$. When solely using one firm for the complete trip, the firm may sell the combined trip at a different bundle price $s_{i i}$. Further, the MaaS supplier may sell a complete cross-network trip at price $s_{i j .}{ }^{5}$ The combined price, $P_{i i}$, for using only firm one is thus $p_{i}+q_{i}$ or $s_{i i}$ if the transport firm offers bundling; a cross-network trip has a combined price $P_{i j}$ of $p_{i}+q_{i}$ or $s_{i j}$ if there is a MaaS supplier that offers bundling.

We have two reference cases without a platform:

- Free competition in which within- and cross-firm services can be used by the traveller. Each firm can set up to three prices: the prices of the service on both links, $\mathrm{p}_{\mathrm{i}}$ and $\mathrm{q}_{\mathrm{i}}$, and a complete trip price with "door-to-door services" (assuming no access before A, or regress after B) from a specific firm with a possible discount $\mathrm{s}_{\mathrm{ii}} \leq \mathrm{p}_{\mathrm{i}}+\mathrm{q}_{\mathrm{i}}$.

- Independent services when there is no cross-firm travel. This latter case gives the minimum profit that firms must make for them to be willing to be part of a platform, as a single firm can always choose not to allow cross-travel by not stopping at the point of intersection between $\mathrm{A}$ and $\mathrm{B}$ where the alternative mode stops.

With a MaaS platform, we consider three different cases (for simplicity, in all three cases we assume that cross-network trips are impossible without using the MaaS platform):

- System Integrator model. The firms set their own price $\left(s_{i i}\right)$ and the platform sets the crosstravel prices $s_{i j}$; the platform keeps an exogenously fixed share $\phi$ of the revenue it generates. This reflects for instance the business structure of Apple computers for hardware components: individual firms sell hardware components to Apple, which integrates these components. The integrator sells the combined (cross-network) services to end users at the price it sets. So in this case there are only bundle prices, and no link prices.

- Platform model. In this model, the transport firms set all prices, and the platform keeps share $\phi$ of the revenues it generates. This reflects the business models of platform firms such as Airbnb, Booking, eBay, Amazon or AliExpress. ${ }^{6}$ The price for an on-network trip of firm $i$ is $P_{i i}=s_{i i}$, and a cross-network trip first using firm $i$ and then firm $j$ has a price of $p_{i}+q_{j}$.

- Intermediary model, transport firms as the leader. Transport firm $i$ sells the segments of the cross-trips to the MaaS supplier at wholesale prices $p_{i}$ and $q_{i}$, and the MaaS supplier sets crosstrips at retail price $s_{i j}$ to the travellers. This model reflects the retail market where intermediaries sell products and services that are bought from manufacturers or wholesalers. An example is Amazon, which buys products from many wholesalers and then sells them online to customers.

\footnotetext{
${ }^{5}$ Non-arbitrage conditions hold: i) the price of the bundle cannot be larger than the price of the individual components $\left(s_{i i} \geq p_{i} ; s_{i i} \geq q_{i} ; s_{i j} \geq p_{i}\right.$; $\left.s_{i j} \geq q_{j}\right)$, and ii) the price of the bundle cannot be smaller than the sum of prices of individual components $\left(s_{i i} \leq p_{i}+q_{i} ; s_{i j} \leq p_{i}+q_{j}\right)$.

${ }^{6}$ Most of these platforms also offer information and payment services. We will omit these extra services and leave it for future work.
} 
As noted above, however, Amazon also operates according to a Platform model. The difference is that now there are two layers of price setting — wholesale and final cross-network prices — and thus extra serial marginalisation; conversely, with the Integrator model, the integrator is the only one that affects cross-network prices.

\subsection{The model}

Consider a representative traveller deriving utility from making trips, described by a quadratic and strictly concave utility function (Singh and Vives, 1984) that allows for imperfect substitutability between the four options:

$$
\begin{gathered}
U\left[Q_{11}, Q_{12}, Q_{21}, Q_{22}\right]=\alpha \cdot\left(Q_{11}+Q_{12}+Q_{21}+Q_{22}\right)-\frac{\beta \cdot\left(Q_{11}^{2}+Q_{12}^{2}+Q_{21}{ }^{2}+Q_{22}{ }^{2}\right)}{2}-\gamma \\
\left(Q_{11} Q_{12}+Q_{11} Q_{21}+Q_{11} Q_{22}+Q_{12} Q_{21}+Q_{12} Q_{22}+Q_{21} Q_{22}\right)
\end{gathered}
$$

$Q_{11}$ is the number of trips using mode or firm 1 for both legs of the trip, $Q_{2 l}$ is the number of trips using first firm 2 and then firm 1, and so on. Here, $\alpha>0, \beta>0$ and $\gamma>0$ are preference parameters. Goods are imperfect substitutes when $\beta>\gamma$.

When setting the marginal utility of income fixed and normalised to $1, U$ also represents Marshallian benefits, and consumer surplus can be written as the following (with $\mathrm{P}_{11}$ being the total price of using firm 1 for both legs of the trip, $\mathrm{P}_{12}$ of using first firm 1 and then 2 , and so on):

$$
C S=U\left[Q_{11}, Q_{12}, Q_{21}, Q_{22}\right]-\left(P_{11} Q_{11}+P_{12} Q_{12}+P_{21} Q_{21}+P_{22} Q_{22}\right)
$$

By having a representative consumer maximise this consumer surplus in (2), we get the following inverse demand (or marginal willingness-to-pay) functions for all trip types; e.g. for $P_{11}:^{7}$

$$
P_{11}=\alpha-\beta Q_{11}+\gamma \cdot\left(Q_{12}+Q_{21}+Q_{22}\right)
$$

Inverting this system yields the direct demand functions, with $D$ denoting quantity demanded; e.g. for $D_{11}$ :

$$
\begin{aligned}
& D_{11}=a-b P_{11}+c \cdot\left(P_{12}+P_{21}+P_{22}\right) \\
& \text { with } a=\frac{\alpha \cdot(\beta-\gamma)}{\delta}, b=\frac{(2 \gamma+\beta)}{\delta}, c=\frac{\gamma}{\delta} \text {, and } \delta=(\beta-\gamma)(\beta+3 \gamma)
\end{aligned}
$$

The newly introduced composite parameters can be interpreted as follows: $a$ is the amount of consumption when all prices are zero, and is the same for all product types because of the assumed symmetry; $b$ is the own-price sensitivity; and $c$ the cross-price sensitivity. Finally, $\beta>\gamma$ must hold for

\footnotetext{
${ }^{7}$ Here, $\alpha$ is the intercept of the inverse demand function and thus the maximum willingness-to-pay. The $\beta$ gives how much the willingnessto-pay changes with the own quantity and the $\gamma$ how much it changes with the quantity of a competing travel option.
} 
the demand system to be consistent, which implies $b>3 c .{ }^{8}$ The condition indicates that, with imperfect substitutes, the sensitivity to all other prices needs to be smaller than that to the own price. As can be seen in Table D.1 in Appendix D, this already gives complicated demand and profit functions for the different supply chain structures. Indeed, we provide simple linear functions as these allow for clear analytical results. We do not expect the functional form of the demands to affect our qualitative results, but, as for instance Choi (1991) finds, this choice of linear demand could affect results. Appendix E tests this for our numerical model by using different functional forms for our demands by adding a second-order term to the own-price sensitivity. It turns out that, for this check at least, our main results are robust to the choice of functional form.

For conceptual transparency we ignore possible economies of scale or fixed costs, as this would mean that changes in market structure would also alter cost, while we want to focus on the isolated impacts via changes in competitive conditions. For further notational ease, we may then next normalise the marginal cost to zero for all links. So in the social optimum, the prices would equal the marginal cost of zero. Yet adding positive marginal costs would not change results: the price equations we give would then represent the markups, above the marginal costs.

As costs are zero by assumption, social surplus equals consumer surplus plus the profits of the transport firms (denoted $P R_{l}$ and $\left.P R_{2}\right)$, plus any profit of the platform $\left(P R_{p}\right)$ :

$$
W=C S+P R_{1}+P R_{2}+P R_{p}
$$

From these functions, we derive the equilibria for prices and profits for the different settings. So each transport firm and MaaS operator chooses a price that maximises its own profits, taking the prices of the other firms as a given. ${ }^{9}$ The resulting profits are given in Table D. 1 in Appendix D for reference. We use game theory to analyse the different business structures. For most structures we use the Bertrand-Nash formulation in which firms choose optimal prices, taking the prices of the other firm as a given. For the Intermediary model, we only consider a Stackelberg-price game. The transport firms are the leaders, and in setting wholesale prices for cross-trips to the platform, they take into account how the platform will react to changes in wholesale price. Such Stackelberg behaviour seems more natural in this case than Bertrand-Nash behaviour, where the wholesalers would take the prices to consumers as a given. Moreover, under the Bertrand-Nash assumption, the Intermediary model would always lead to equilibria with zero cross-trips (and in effect no platform, which defeats the purpose of analysing the Intermediary model). ${ }^{10}$

\footnotetext{
${ }^{8}$ Since $b=\frac{2 \gamma+\beta}{\delta}>\frac{2 \gamma+\gamma}{\delta}=3 c$.

${ }^{9}$ The profit maximization of each firm is characterised by the first-order conditions by differentiating the profit functions with respect to the price variables. From these we can then solve for the equilibrium prices, and thus demands and profits.

${ }^{10}$ Under Nash behavior, a transport firm would take the final price of the platform as a given, and thus also the quantity is seen as fixed; consequently, the firm believes that raising the wholesale price always increases its profit. Accordingly, we would always end up with very high wholesale prices, and the intermediary being unwilling to sell any cross-trips.
} 


\section{Analytical analysis}

\subsection{The effects of providing cross-network transport options}

We consider two cases without MaaS as references: a situation with and one without crossnetwork services. In both cases, providers maximise their profit and take the prices of the other firm as a given. The resulting Bertrand-Nash equilibrium profits and prices are given in Table 1; Table D.1 in Appendix D gives profit objectives that the operators maximise. This analysis serves two purposes: (a) we examine the effects of cross-supply on prices and profits and (b) it provides benchmarks for the business structures with the MaaS provider.

Comparing the equilibrium prices for the two bundles $s_{i i}{ }^{*}$ (asterisks represent equilibrium outcomes) in Table 1, we find that the prices for the cases with cross-network supply are lower than without cross-network supply, except for the obvious case when the cross-price sensitivity $c$ is 0 (remember that $b>3 c$.) Hence, the introduction of cross-network competition lowers the prices, from which travellers benefit. The price of the within-network bundle, $s_{i i}$, is lower than the price of the crossnetwork bundle $p_{i}+q_{j}$. Finally, profits of the firm providing both services are higher than firms that only provide the direct services. Thus, there is also an incentive for firms to provide cross-network services. For simplicity we assume that the operator has zero costs; if it had positive costs then our price equations would be the markups on top of the marginal cost (which is assumed to be zero).

In this setting we do see "serial marginalisation" as in Economides and Salop (1992), and the full price $P$ for a cross-network trip is higher than for an in-network trip. Each firm independently maximises profits and ignores the externality that raising the price on the one link ( $p$ or $q$ ) lowers the profit of the other firm by depressing demand. So, given $s_{12}$ and $s_{22}$, these prices $p_{1}, p_{2}, q_{1}$ and $q_{2}$ are higher than what a monopolist would ask, and lowering them would raise both aggregate profits and consumer surplus. But of course such collusive behaviour is not possible in a Nash setting. We will see later that a MaaS supplier may remove such serial marginalisation, and this may then benefit consumers and firms. However, it may also add an extra layer of serial marginalisation, which would work the other way. The ultimate outcome depends on which of the three MaaS models will prevail.

Table 1: Price, profit and demand equilibria for the supply chain structures "free competition" and the "independent services" structure

\begin{tabular}{|l|c|c|}
\hline & Free Competition & Independent Services (without cross-network trips) \\
\hline Prices & $s_{i i}^{*}=\frac{a}{2 b-5 c}$ & $s_{i i}^{*}=\frac{a(b+c)}{2 b^{2}-3 b c-3 c^{2}}$ \\
\hline & $p_{i}^{*}=q_{i}^{*}=\frac{2 a}{6 b-15 c}$ & \\
\hline Profit & $\pi_{i}^{*}=\frac{a^{2}(17 b-32 c)}{36 b^{2}-180 b c+225 c^{2}}$, & $\pi_{i}^{*}=\frac{a^{2}\left(b^{3}+2 b^{2} c+b c^{2}\right)}{4 b^{4}-12 b^{3}-3 b^{2} c^{2}+18 b c^{3}+9 c^{4}}$ \\
\hline
\end{tabular}


Now we turn to the first form of MaaS supply. The transport firms set the own price $\left(s_{i i}\right)$, and the platform sets the cross-travel prices $s_{12}$ and $s_{21}$; the platform keeps a share $\phi$ of revenue. Each operator and the integrator set their prices to maximise their own profits (see Table D.1), and each competes in a Bertrand fashion by taking the prices of the others as given. Table 2 gives the resulting BertrandNash equilibrium profits and prices. The integrator setting leads to two changes to the market structure.

i) While free competition without MaaS has "serial-marginalisation" externalities in the prices of cross-network services, the integrator internalises these and thus removes the serial marginalisation. This lowers cross-network prices, and this in turn leads to lower innetwork prices by increasing competition.

ii) There are now in effect three transport suppliers: Firm 1, Firm 2 and the MaaS operator. This intensifies competition and lowers prices.

Both these effects benefit consumers by lowering prices. Conversely, the removal of serial marginalisation raises transport-firm profits, while the extra competitor lowers their profits. Table 2 presents the results. ${ }^{11,12}$

Table 2: Price, profit and demand for the System Integrator model of the supply chain structure

\begin{tabular}{|l|c|}
\hline Prices & Nash equilibria for the System Integrator model \\
\hline $\begin{array}{c}\text { Profit } \\
\text { transport }\end{array}$ & $s_{11}^{*}=s_{22}^{*}=\frac{2 a b-(\varphi-1) a c}{4 b^{2}-6 b c+(2 \varphi-4) c^{2}}$ \\
\hline $\begin{array}{c}\text { Profit } \\
\text { platform }\end{array}$ & $s_{12}^{*}=s_{21}^{*}=\frac{2 a b+a c}{4 b^{2}-6 b c+(2 \varphi-4) c^{2}}$ \\
\hline
\end{tabular}

Proposition 1: The System Integrator setting lowers all prices compared with the free-competition case, and thus raises demands, consumer surplus and social surplus (as prices get closer to the marginal costs of zero). The price decreases are larger when demand is less sensitive to the own price (i.e. smaller $b$ ), more sensitive to the price of the other travel options (i.e. larger $c$ ), and when the integrator keeps a larger share, $\phi$, of revenue.

Proposition 2: Transport firm profits can be lower or higher with the Integrator model than with free competition: the integrator removes the serial marginalisation that hurts profi, but effectively acts as a third supplier, and this raises competition. Transport firms' profits with the Integrator model are larger than with free competition when the revenue share for the platform is not too large and the travel options are not too strong a substitute; the parameter conditions are:

\footnotetext{
${ }^{11}$ We see that profits of transport providers decrease with $b$ and decrease with $\phi$. Profits of the MaaS integrator decrease with $b$ but quite intuitively increase with $\phi$.

${ }^{12}$ For all MaaS cases we assume away the option of cross-network trips that do not use the MaaS supplier, and this market seems an interesting option for further research.
} 
- $\phi<\frac{1}{2 c^{2} \cdot\left(18 b^{2}-81 b c+97 c^{2}\right)}\left(-72 b^{4}+396 b^{3} c-658 b^{2} c^{2}+213 b c^{3}+163 c^{4}+3(2 b-\right.$ 5c) $\left.\sqrt{144 b^{6}-864 b^{5} c+1784 b^{4} c^{2}-1200 b^{3} c^{3}-423 b^{2} c^{4}+658 b c^{5}+225 c^{6}}\right)$

- $c<\frac{2}{(9+\sqrt{19})} b$

Proofs for Propositions 1-2 can be found in Appendix A.

The price decreases can be rather large. If the travel options would be perfect substitutes and thus $b=3 c$, the price decrease would be $50-62.5 \%$ for in-network trips, and $62.5-67.2 \%$ for cross-firm trips, where the exact percentages depend on the share $\phi$ the integrator gets of revenue. Hence, in this setting, MaaS supply has the advantage of lowering prices. If demand would be perfectly elastic with respect to the own price $(b=\infty)$, all prices are always zero, and, so in this extremum, the price decreases from the intermediary reach zero. When $c=0$, the demands would be independent of the prices of the other options, and hence the price of in-network trips that only use a single firm is unaffected by the presence of the platform. Under $c=0$, the cross-trip prices would be $25 \%$ lower with the Integrator model than under free competition, as the integrator still removes serial marginalisation.

Transport firm profits are larger with the Integrator model than with the no-cross-network trips of the independent services unless demand is really insensitive to the own price (i.e. low $b$ ) and/or really sensitive to other prices (i.e. high $c$ ). So typically, firms will not have an incentive to stop supplying cross-network trips, but this may be a problem in some parameter ranges.

We conclude that MaaS with an integrator setting the cross-network prices leads to lower prices than under free competition. Travellers benefit, and demand for transport services will increase. The profits of transport providers may rise or fall depending on the parameters. Naturally, besides these pricing benefits, in reality we would also get benefits from the ease of use of Maas and information provision, which would raise the demand for multimodal transport.

\subsection{Analysis of the Platform model}

This section discusses the Platform model, in which the transport firms set the prices for the direct services $s_{i}$ and for their parts of the cross-network services $p_{i}$ and $q_{i}$. The MaaS operator only offers a platform on which the cross-network services are sold, and unlike with the Integrator model there is no bundling of cross-network trips. The price for a cross-network trip is the sum of prices charged by the operators for using their links, while a fraction $\phi$ of the revenues remains with the MaaS operator. Just like before, the operator maximises its own profits and competes in a Bertrand fashion.

The Nash equilibria are presented in Appendix B in Table B.1, as they are even messier than the previous ones. Here, we will review the results. The prices of the direct services of the platform model are lower than with free competition, and so demand is higher. For cross-network services we see that prices are higher for the platform model compared to the reference model. 
Proposition 3: The Platform model of the MaaS supplier leads to higher prices than the Integrator model, and thus it leads to lower consumer and social surpluses. Compared with the free-competition case, the Platform model leads to lower prices for in-network trips but higher prices for cross-network trips, and thus consumer surplus and welfare can be higher or lower.

Proposition 4: The platform setting always leads to lower profits for the transport firms than under the free-competition setting. Compared to the Integrator model setting, the Platform model can lead to higher or lower transport firm profits depending on the revenue share for the MaaS supplier and the ratio of demand sensitivities, b/c. Fig. 2 illustrates these parameter ranges.

Proofs for Propositions 3-4 can be found in Appendix B.

Fig. 2. The platform gives higher profits in the grey parameter region and the intermediary in the

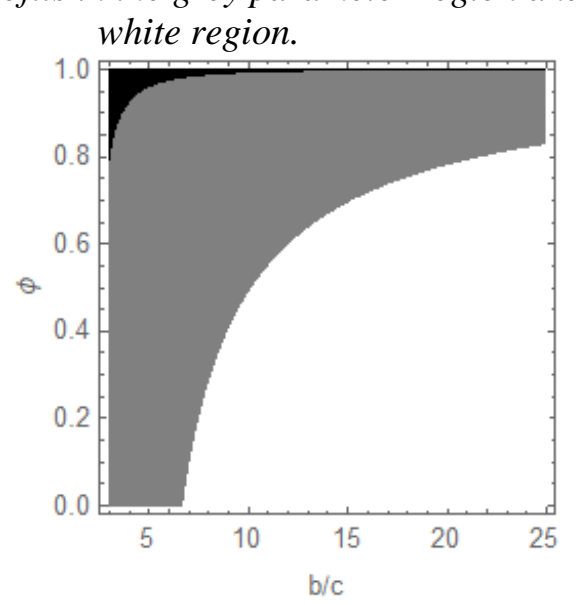

Note: In the black region, there is a corner solution with no supply of MaaS trips with a platform

To conclude, the Platform model—with transport providers setting all prices and no bundling — yields lower equilibrium prices for the direct services and higher cross-network prices, promoting usage of direct services. The effects of the introduction of a platform on the transport firm profits are negative compared to the free-competition setting, and the effects on demand are positive. On the whole, this model of MaaS seems an attractive one, but less so than the Integrator setting.

\subsection{Analysis of the Intermediary model}

Now consider the Intermediary model, in which transport firms set the prices for the direct services and the wholesale prices for services provided by the platform. The platform sets the prices for the travellers using cross-network services. For this model we adopt a Stackelberg game. First, the transport providers set their prices for the direct services and the wholesale cross-network prices. Thereafter, the intermediary sets the cross-network prices as seen by the customers. The two transport providers compete Bertrand-Nash amongst themselves, but each is a leader towards the intermediary, setting wholesale prices while taking into account how the platform will respond to their wholesale price. Based upon this, we derive the profits and demands. The detailed results are presented in Appendix C in Table C.1. Here, we will overview the more important results. 
Comparing this supply chain structure with the reference model of free competition, we find that the prices resulting from this intermediary model are higher than the prices of the reference model. With increasing price sensitivity (higher $b$ ), this difference decreases.

Proposition 5: The Intermediary model leads to higher prices than the Integrator model, and even than the free-competition setting. ${ }^{13}$

Proposition 6: The Intermediary model can lead to higher or lower transport-firm profits than the Integrator model and free-competition settings depending on the ratio of demand sensitivities $\mathrm{b} / \mathrm{c}$ and $\phi .{ }^{14}$

Proofs for Propositions 5-6 can be found in Appendix C.

It can be concluded that the model in which the platform acts as an intermediary is not very attractive for travellers because of the high prices. An important mechanism behind this result is the combination of Stackelberg behaviour of the service operators in combination with extra double marginalisation that is introduced, ${ }^{15}$ with both the transport operators and the MaaS operator trying to skim off the same consumer surplus. Still, this setting is also not particularly attractive for the transport firms, since profits can be higher or lower than in the other settings, and it seems likely that the profits will be similar in all cases.

\section{Numerical analysis}

In this section, we compare the outcomes of the different business models using a numerical example. The analytics showed that some MaaS structures have better or worse effects for consumers or transport firms, and that for others it depends on the parameters. But how large are the effects on prices, profits and consumer surplus? How strongly do results depend on parameters? For this we need a numerical model. We will start with our base case numerical model, and thereafter we will look at sensitivity analyses where we change some of the more important parameters.

\subsection{Base case numerical example}

Let us consider a market with at maximum 100000 trips for each of the four services when all fees are zero, hence $a=100000$. We assume an own-price elasticity of -0.4 for the transport services in the free-competition case. This results in $b=20000$ and $c=4000$. Assume that the share of revenue for the platform (when relevant) is $\phi=0.02$. Informal statements by people involved in the negotiations reveal such shares are on the table to be discussed. This share appears in the discussions between

\footnotetext{
${ }^{13}$ Note again that for simplicity we assume that the operator has zero costs; if it were to have positive costs then our price equations would be the markups on top of the marginal cost (which is assumed as zero).

${ }^{14}$ Note that $\phi$ only affects the profits with the Integrator model and is irrelevant for the Intermediary model and under free competition.

${ }^{15}$ Although, as argued in Section 2, full Nash-Bertrand would be even worse than our Stackelberg setting, as it would always lead to crossnetwork trip prices that are so high that there are no cross-trips. As then there basically would be no MaaS, we focus on the Stackelberg setting instead, which as argued also seems a more logical way to compete in this setting.
} 
transport operators and MaaS service providers, ${ }^{16}$ although ride-sourcing services such as Uber require a much larger share (up to $35 \%$ ). Based on these assumptions, we can compare equilibrium prices and profits for each of the business models. The results are presented in Table 6. The sensitivity analysis will focus on the effects of changing $b, c$ and $\phi$.

Table 3: Results of the different market structures under the base calibration

\begin{tabular}{c|c|c|c|c|c|c}
\hline & $\begin{array}{c}\text { Free } \\
\text { competition }\end{array}$ & $\begin{array}{c}\text { Independent } \\
\text { services }\end{array}$ & $\begin{array}{c}\text { Marginal cost } \\
\text { pricing }\end{array}$ & $\begin{array}{c}\text { System } \\
\text { Integrator }\end{array}$ & Platform & Intermediary \\
\hline$P_{11}=P_{22}$ & 5.000 & 4.688 & $0=M C$ & 4.157 & 4.989 & 5.312 \\
\hline$P_{12}=P_{21}$ & 6.666 & $N A$ & $0=M C$ & 4.164 & 6.678 & 7.927 \\
\hline$Q_{11}=Q_{22}$ & 73333.3 & 93750 & 100000 & 66808.0 & 73601.3 & 78434.7 \\
\hline$Q_{12}=Q_{21}$ & 33333.3 & 0 & 100000 & 66626.3 & 33061.8 & 15653.3 \\
\hline Consumer surplus & 2233330 & 2197270 & 7500000 & 3338890 & 2291760 & 1947140 \\
\hline $\begin{array}{c}\text { Transport firm's } \\
\text { profit }\end{array}$ & 588890 & 439453 & 0 & 549585 & 583571 & 525387 \\
\hline Platform's profit & $N A$ & $N A$ & $N A$ & 11100 & 8828 & 30626 \\
\hline Social surplus & 3411110 & 3076170 & 7500000 & 4448650 & 3411880 & 2987600 \\
\hline Relative efficiency & 0 & -0.0819 & 1 & 0.2537 & 0.0002 & -0.1036 \\
\hline
\end{tabular}

Note: Marginal costs are normalised to zero, and we assume that there are neutral scale economies and no fixed cost. Social surplus $=$ Consumer surplus + Transport firms ' profits + MaaS supplier profit. Relative efficiency is the gain in social surplus of a policy from the base case of free competition and no MaaS relative to the gain of going to the first-best outcome of marginal cost pricing.

Table 3 shows a number of results:

- The prices with free competition are higher than the prices with independent services, and so are the profits of the transport firms. In absence of costs to make services of different firms compatible for travellers, firms have an interest in supplying cross-network services, and to charge higher prices for this. This result matches insights from the literature on standardisation.

- For the Integrator model, prices are lower than in the free-competition case, as the Integrator platform basically is a third competitor and removes serial marginalisation. Total profits are slightly lower, but firms would not choose to stop supplying to the platform.

- For the Platform case, profits for the firms are higher than for the Integrator case, and the profit for the platform is lower. Consumers face higher prices but are better off than in the freecompetition case. Hence, under the base parameters, this seems a good option but less so than the Integrator model.

- The Intermediary model adds extra serial marginalisation, as now there are three price setters for the cross-network trips. Prices are high, and profits low. Accordingly, this does not seem to be an attractive setting. This does assume that the platform does not increase travel demand in

\footnotetext{
${ }^{16}$ Transport providers in Belgium offer third parties selling their mobile tickets fixed fee of 6 eurocents per ticket or about $2 \%$ of the ticket price.
} 
another way than through pricing, e.g. by making it easier to make cross-firm trips, but the same holds for all three MaaS settings.

These results suggest that both the Integrator model and the Platform model seem to contribute to realising cross-network services with lower prices than would result from free competition. The difference between these two models is the actor who sets the cross-network prices; in case of the Integrator model this is the platform, in case of the Platform model this is done by the transport providers. This is also reflected in the allocation of profits; in the former case the platform profits are higher, and in the latter case the transport providers get higher profits.

\subsection{Sensitivity analyses}

Now we turn to sensitivity analysis of our numerical model to see how robust our results are, when each policy is better for profits or welfare and what the effects are of parameters. We will focus on prices, profits and social surplus. We will study the three MaaS models and compare their outcomes to the reference case of free competition. As the demand functions are the same in all settings, a lower price for a service always means a higher demand for that service, a higher total demand and a higher consumer surplus. Besides all of this, a test illustrated in Appendix E shows the effects of adopting different functional forms for the demand functions and finds that our qualitative results seem robust.

\subsubsection{Sensitivity analysis: System Integrator vs free competition without MaaS}

Let us first consider the Integrator model. Figures 3 and 4 show the changes from the freecompetition setting. Fig. 3 does this over ranges $\phi$ (share of revenue going to the platform) and Fig. 4 over ranges of $b$ (own-price sensitivity) for three levels of $c$ (cross-price sensitivity, i.e. the sensitivity to the prices of the other options). As the analytics predicted, the MaaS supply via Integrator lowers the prices by removing the serial marginalisation. Hence, the price drop is especially large for crossnetwork trips. The lowered prices also raise consumer surplus. Because prices become closer to the zero marginal costs, social surplus also increases. Transport firm profits fall unless the own-price sensitivity is very large (i.e. very large $b$ ).

The introduction of the Integrator model removes serial marginalisation — which raises profitsand leads to more competition - which lowers profits. With a high b, competition is always intense and profits low, so the competition effect of the Integrator is weak, and thus even the firms benefit. Note again that for simplicity we ignore any demand-increasing effect (i.e. a shift of the demand function rather than along the demand function) that MaaS may have. So in reality the Integrator is likely to be even more beneficial.

Orices change less in percentage terms when demand is more own-price sensitive, and prices change more when $c$ is larger. The effect on consumer surplus and welfare changes is non-monotonic and depends on the interplay of $c$ and $b$. Finally, the boundary $b>3 c$ for a working demand system is clearly visible, as the functions become asymptotically vertical at this point. 
Fig.3: Effect of $\phi$ (share of revenue going to the platform) on the changes from going from free competition with no MaaS to the Integrator setting

(a) Price for direct services

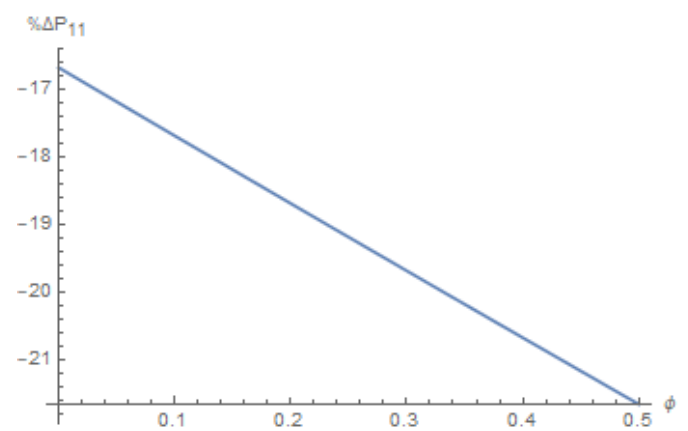

(b) Price for cross-network trip using Integrator

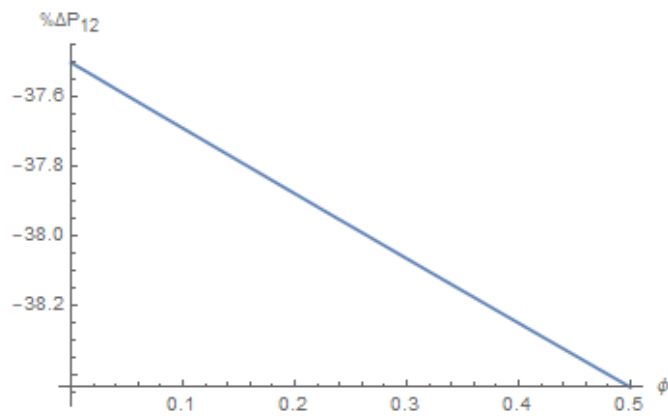

(c) Transport firm profits

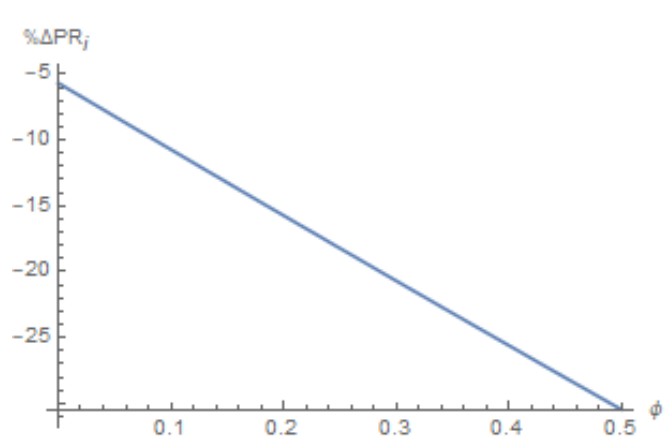

(d) Consumer surplus

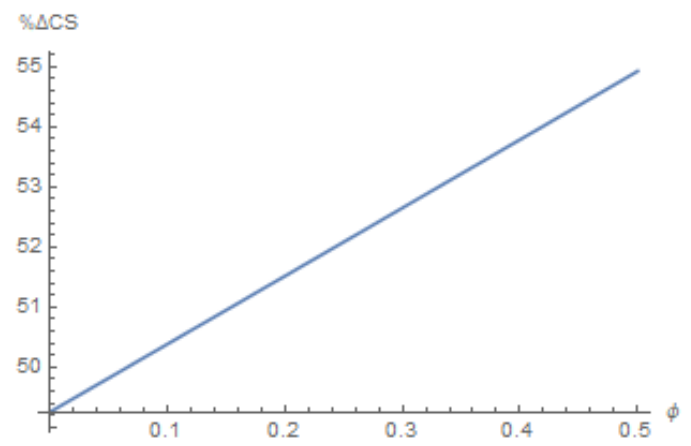

(e) Welfare

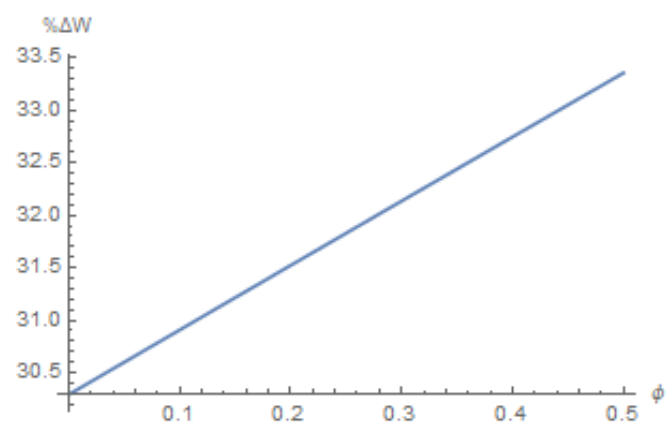

Fig.4: Effect of b (own-price sensitivity) and c (cross-price sensitivity) on the changes from going from free competition with no MaaS to the Integrator setting

(a) Price for direct services

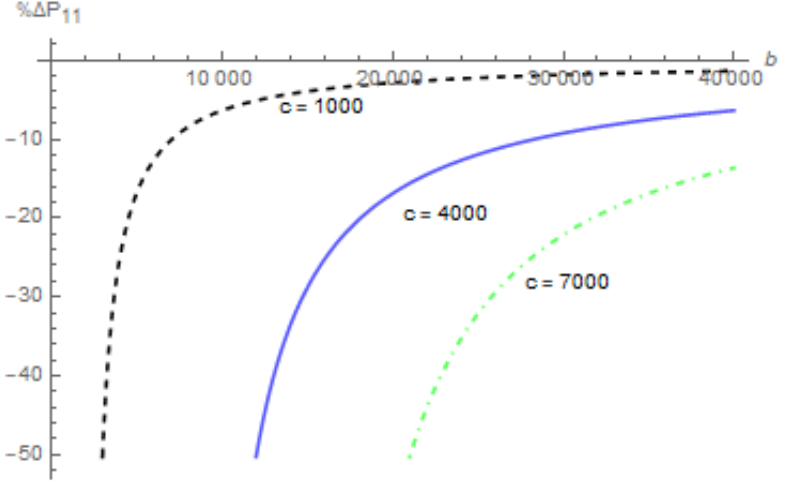

(c)Transport firm profits (b) Price for cross-network trip using Integrator

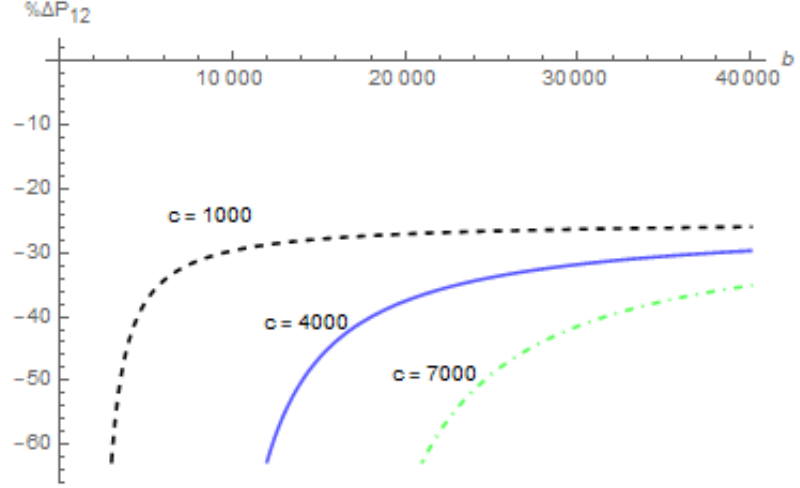

(d) Consumer surplus

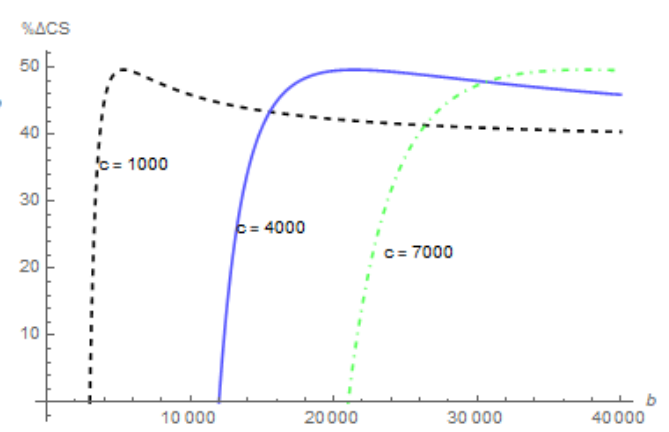

(e) Social surplus

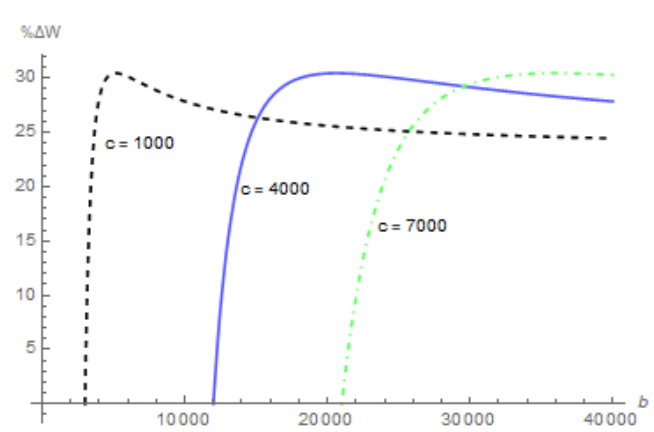




\subsubsection{Sensitivity analysis: Platform model vs free competition with no MaaS}

Now we turn to the changes that the Platform model causes from the free-competition setting without MaaS. Just as in the previous analysis, we will do so for $\phi$ in Fig. 5 and for $b$ in Fig. 6. The introduction of MaaS via the Platform model has two effects on price setting. First, MaaS basically becomes a third supplier that supplies cross-network transport and so creates more competition for in-network trips and thus lowers their prices $P_{11}$ and $P_{22}$. Second, MaaS uses the trips made by the transport firms, and consequently it causes even more serial marginalisation for the cross-trips and raises these prices $P_{12}$ and $P_{21}$. It therefore depends on the parameters whether consumer surplus and social surplus are higher or lower with the Platform model than without MaaS, although for social surplus this is hard to see. The lower the share going to the platform or the less price-sensitive demand, the better the Platform setting performs compared to the setting without MaaS.

Fig.5: Effect of $\phi$ (share of revenue going to the platform) on the changes from going from free competition with no MaaS to the Platform setting

(a) Price for direct services

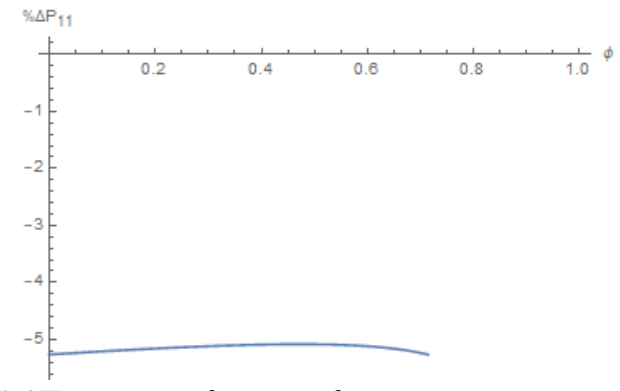

(c)Transport firm profits (b) Price for cross-network trip using Platform

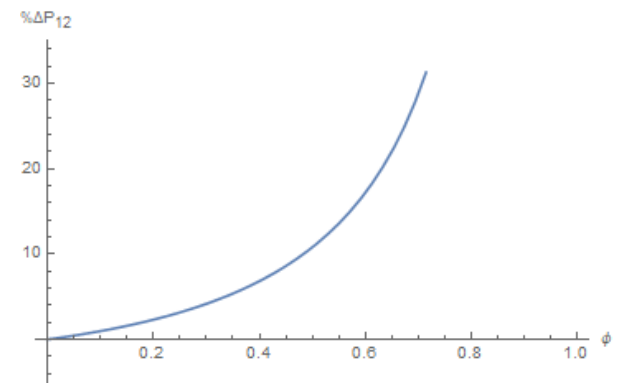

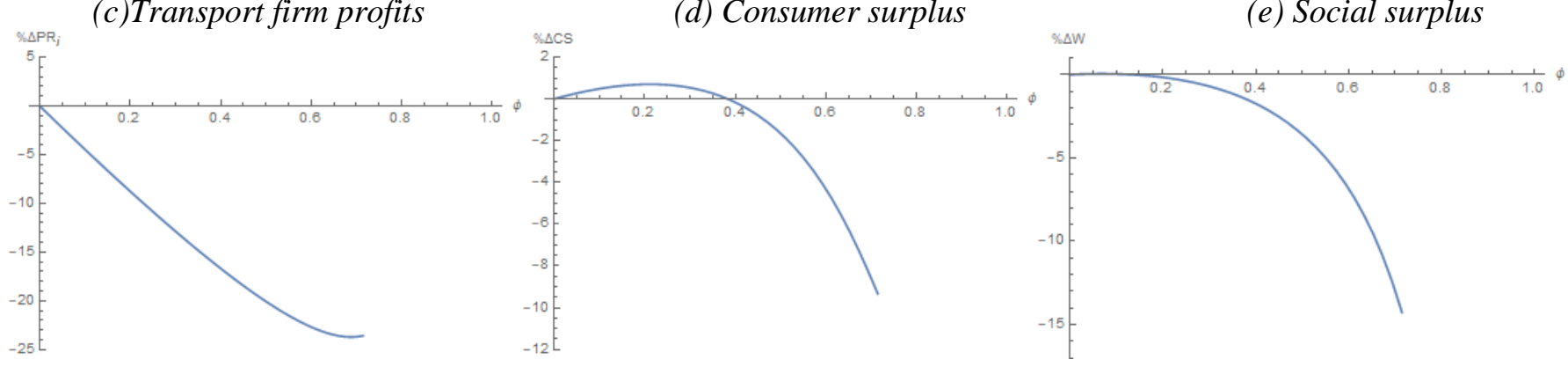


Fig.6: Effect of b (own-price sensitivity) on the changes from going from free competition with no MaaS to the Platform setting

(a) Price for direct services

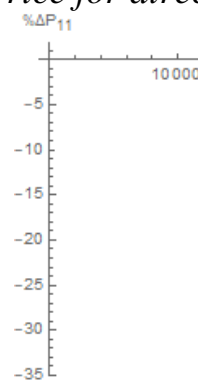

(b) Price for cross-network trip

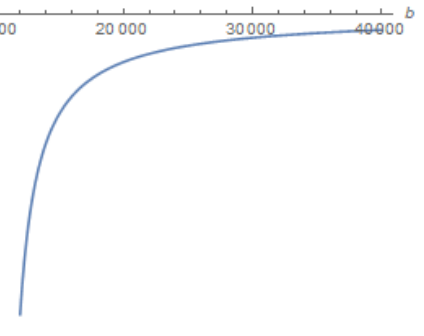

(d) Consumer surplus

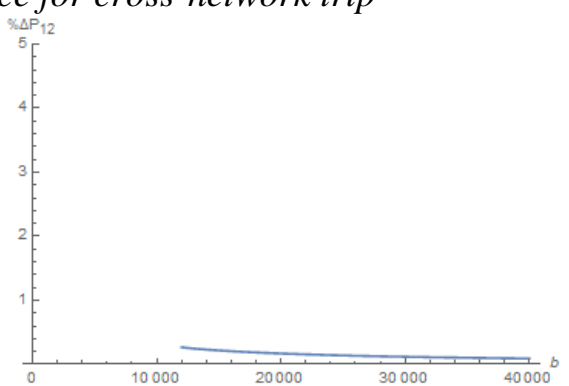

(e) Social surplus
(c)Transport firm profits

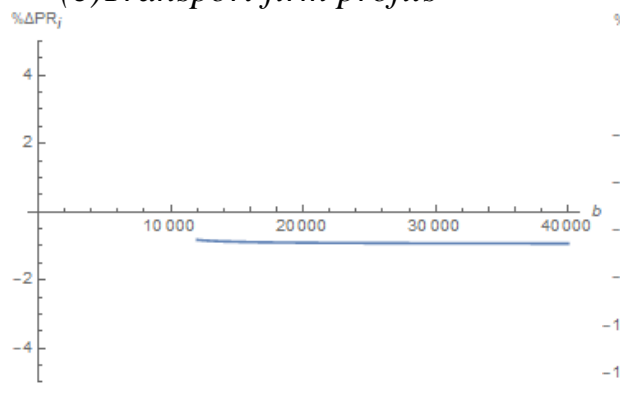

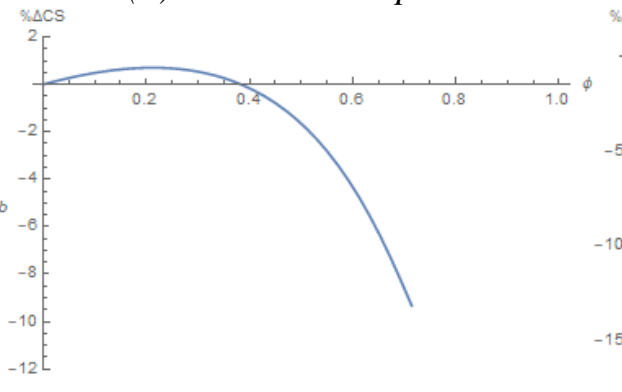

Sod
-5
-15

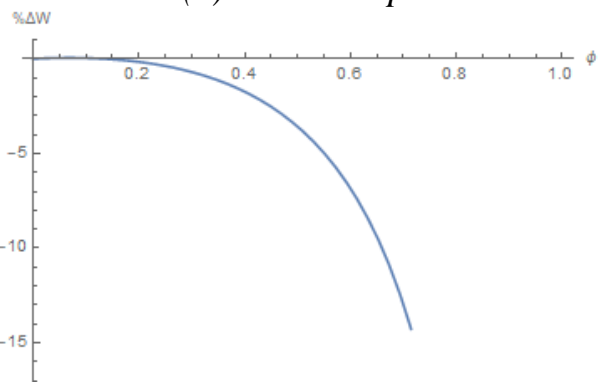

\subsubsection{Sensitivity analysis: Platform model vs Integrator model}

Now we turn to comparing the Platform model of MaaS to the Integrator model of MaaS, and look at the effect of $\phi$ in Fig. 7 and $b$ and $c$ in Fig. 8. As predicted by the analytics, the Platform model always has higher prices and thus lower consumer and social surpluses. It depends on the parameters as to which setting has the higher transport firm profits. The Platform setting does relatively better for the firms when the share going to the MaaS supplier is lower, demand is less sensitive to the own price, and demand is more sensitive to the price of other transport options. 
Fig.7: Effect of $\phi$ (share of revenue going to the platform) on the changes from going from the Integrator setting to the Platform setting

(a) Price for direct services network trip

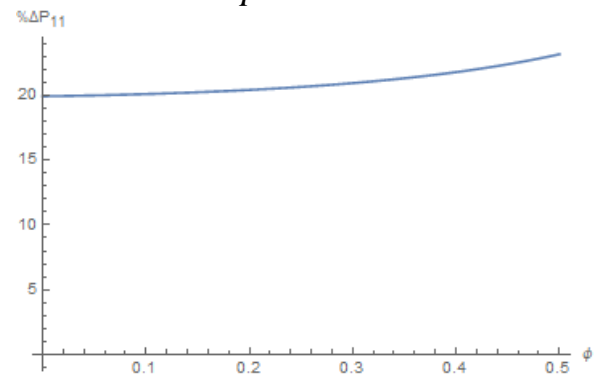

(c) Transport firm profits (b) Price for cross-

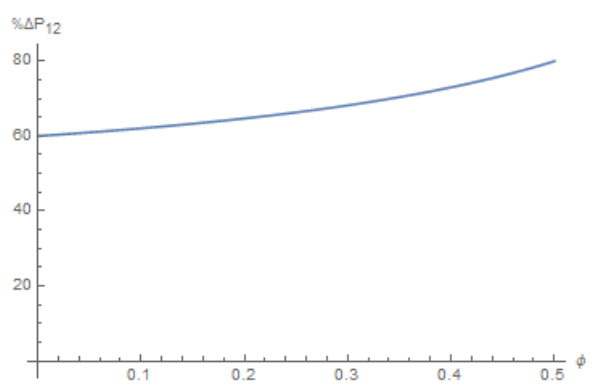

(d) Consumer surplus (e) Social surplus

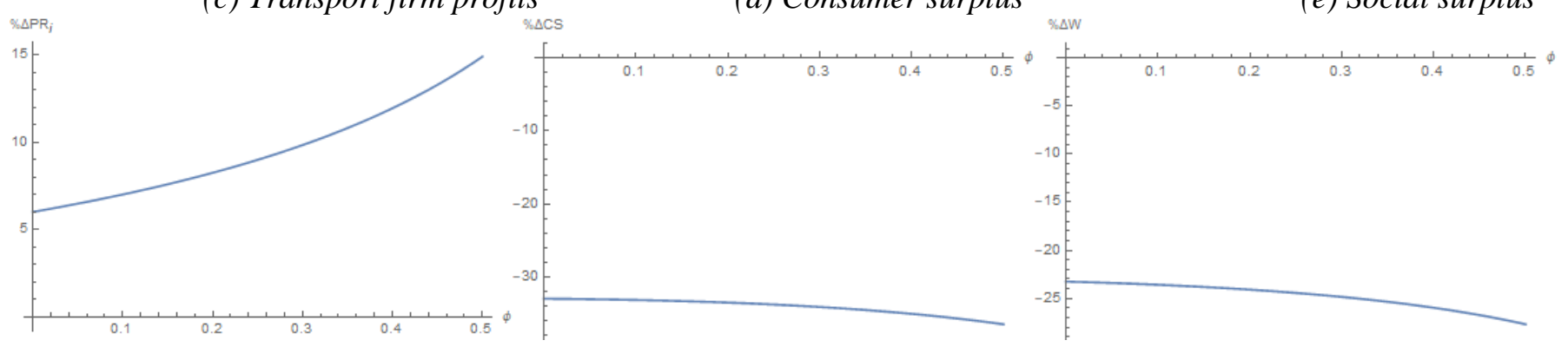

Fig.8: Effect of b (own-price sensitivity) and c (cross-price sensitivity) on the changes from going from the Integrator setting to the Platform setting

(a) Price for direct services

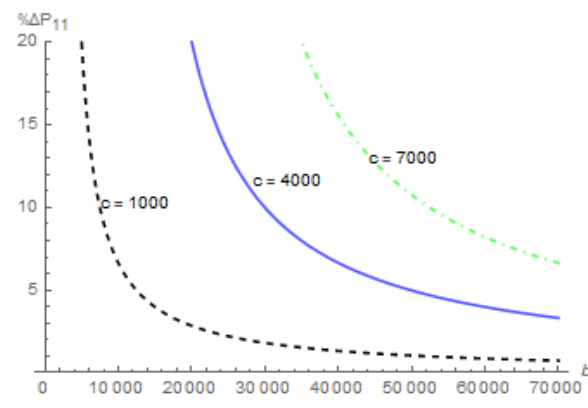

(c) Transport firm profits (b) Price for cross-network trip

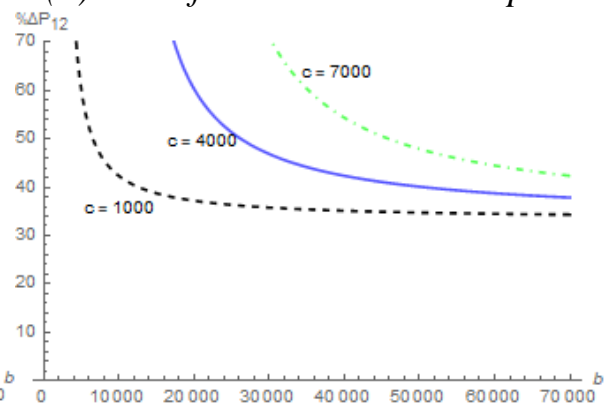

(d) Consumer surplus

(e) Social surplus
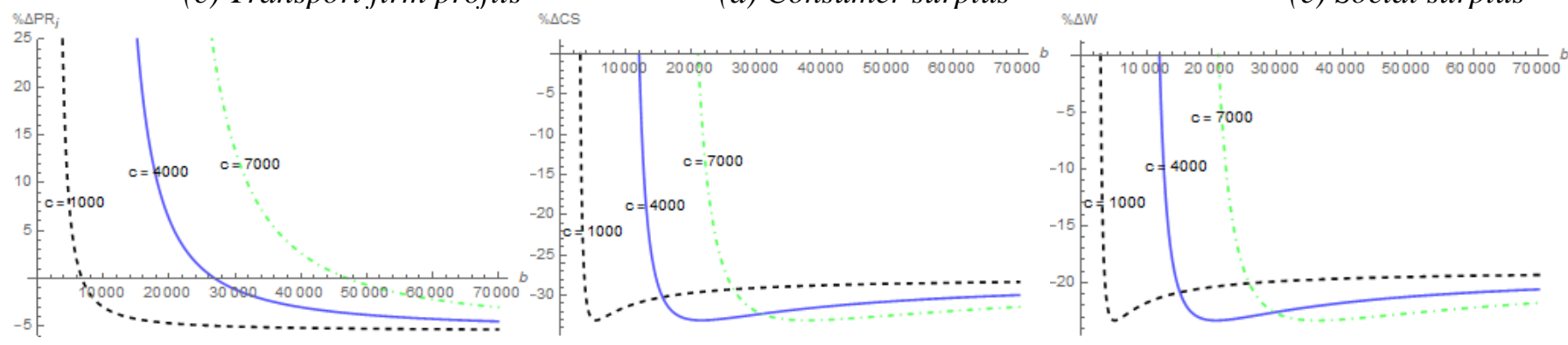

\subsubsection{Sensitivity analyses for the Intermediary model}

Finally, we turn to the sensitivity analyses for our third form of MaaS supply: the Intermediary model. We will focus on the effects of the own-price sensitivity, as it is most interesting. Fig. 9 shows 
that the Intermediary model leads to much higher prices than even the Platform model, and thus to lower social surplus, where the Platform model leads to higher prices than the Integrator model. It depends on the parameters as to whether profits are higher or lower. Finally, Fig. 10 show that prices are also much higher with Integrator than without any MaaS. The Intermediary setting tends to perform better for customers when demand is more sensitive to the own price, as this intensifies competition and lowers markups in all settings. Thus, the Intermediary model does not seem to be an attractive option for MaaS supply. Platform and especially Integrator seem much better.

Fig.9: Effect of b (own-price sensitivity) on the changes from going from the Platform setting to the Intermediary setting

(a) Price for direct services

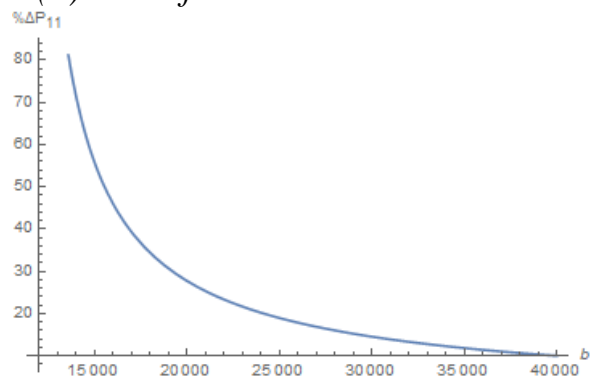

(b) Price for cross-network trip

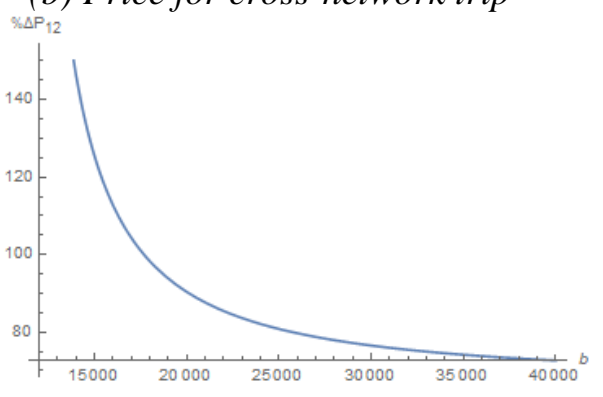

(c) Profit

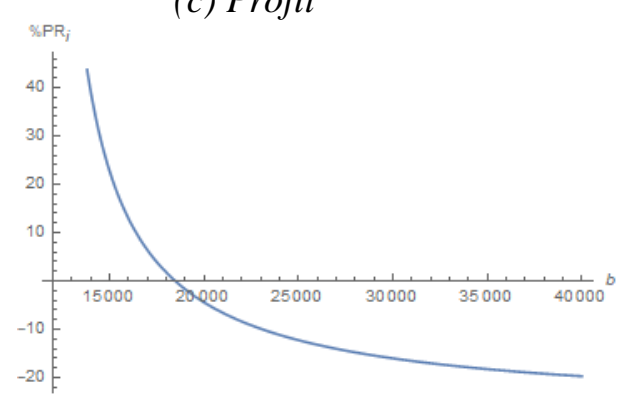

Fig. 10: Effect of b (own-price sensitivity) on the changes from going from the freecompetition setting without MaaS to the Intermediary setting

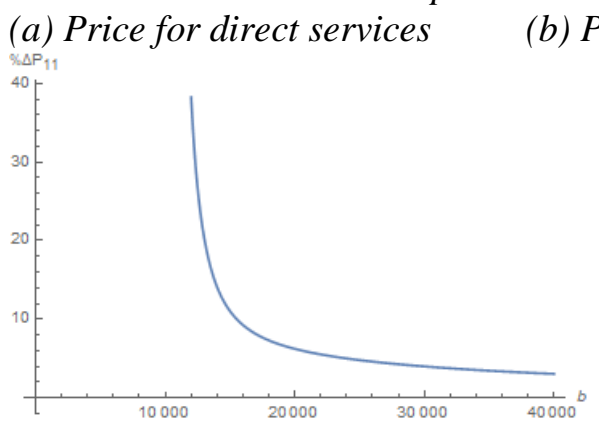

b) Price for cross-network trip

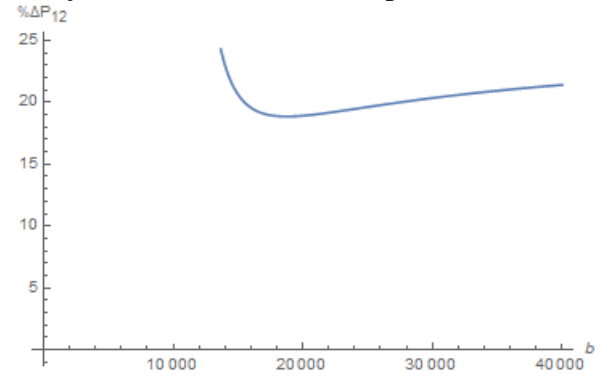

(c) Profit

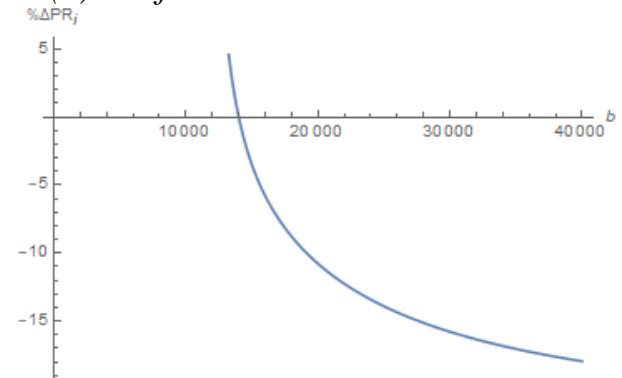

\section{Regulation of wholesale prices}

\subsection{Introduction}

It has been argued (e.g. Ecorys, 2015) that transport providers should offer their services at marginal costs to the platforms, or at collectively agreed wholesale prices. To be able to offer mobility services, platforms need access to public transport services and possibly other additional transport services, to the payment systems with which customers can pay for their journeys and to data (including travel information) with which travellers can make travel plans. Without access to the relevant services, platforms cannot enter the market for mobility services. Mobility service providers currently have limited access to the range of public transport services and prices offered 
by these firms. For example, (certain) transport firms do not offer access to discount products, and (some) carriers can unilaterally adjust the agreements. This often implies that mobility service providers can only offer public transport services to private individuals at full-rate retail prices. As a result, mobility service providers cannot match the offers of transport firms that do sell various products with discounts to travellers.

One option to realise a level playing field is to require that transport firms offer these services at marginal costs (or a fixed and commonly agreed wholesale price) to the platforms. This was suggested by Economides and Salop (1992) under the name "one-sided joint price setting" or "onesided regulation". In this section, we will evaluate the general analysis of this for MaaS applications.

\subsection{Analytical model}

In this case transport firms have to sell cross-network trips at marginal costs. Two problems with this setting are that the government needs enormous amounts of information to verify the quoted marginal costs, and that transport firms would take losses if there are economies of scale (which we assume away by using constant marginal costs). Perhaps more realistic, but even more informationintensive, would be allowing "some" profit. The current setting can be seen as an extreme ideal case that is best for consumers and social surplus. The platform maximises its profit by setting the crossprices ( $\mathrm{s}_{12}$ and $\left.\mathrm{s}_{21}\right)$, taking these input costs as a starting point. Table 4 overviews the results.

Table 4: Analytical outcomes with wholesale regulation

\begin{tabular}{|c|c|}
\hline $\begin{array}{c}\text { Equilibrium } \\
\text { prices }\end{array}$ & $s_{11}=s_{22}=\frac{a b}{2 b^{2}-3 b c-c^{2}}$ \\
$s_{12}=s_{21}=\frac{a \cdot(2 b+c)}{4 b^{2}-6 b c-2 c^{2}}$ \\
\hline $\begin{array}{c}\text { Equilibrium } \\
\text { profits }\end{array}$ & Transport providers: \\
& $a^{2} b^{3}$ \\
\hline$c^{4}+6 b c^{3}+5 b^{2} c^{2}-12 b^{3} c+4 b^{4}$ \\
Platform: \\
$\frac{-1 *\left(a^{2} c^{3}+3 a^{2} b c^{2}-4 a^{2} b^{3}\right)}{2 c^{4}+12 b c^{3}+10 b^{2} c^{2}-24 b^{3} c+8 b^{4}}$ \\
\hline
\end{tabular}

\subsection{Numerical model}

Let us now return to the numerical model. Table 5 compares the effects of the regulated case to the unregulated cases. In this situation travellers will benefit, since they will experience much lower prices. The transport firms will experience much lower profits, even in comparison with the case without cross-network services. Hence, they are unlikely to be willing to participate (unless they get a higher fee for cross-trips than just the marginal cost). This case is unlikely to be accepted by the transport firms, due to the much lower profit than the free-competition or independent services 
cases, and they also have lower profits than with the Integrator model. Compared to the Integrator model, direct trips have much lower prices, while for cross-trips the benefit is much smaller.

Table 5: Numerical outcomes with wholesale regulation under the base calibration

\begin{tabular}{c|c|c|c|c|c}
\hline & $\begin{array}{c}\text { Free } \\
\text { competition }\end{array}$ & $\begin{array}{c}\text { Independent } \\
\text { services }\end{array}$ & $\begin{array}{c}\text { System } \\
\text { Integrator }\end{array}$ & Platform & Regulated \\
\hline$P_{11}=P_{22}$ & 5.000 & 4.688 & 4.157 & 4.989 & $\mathbf{3 . 6 7 6}$ \\
\hline$P_{12}=P_{21}$ & 6.666 & $N A$ & 4.164 & 6.678 & $\mathbf{4 . 0 4 4}$ \\
\hline$Q_{11}=Q_{22}$ & 73333.3 & 93750 & 66808.0 & 73601.3 & $\mathbf{7 3 5 2 9 . 4}$ \\
\hline$Q_{12}=Q_{21}$ & 33333.3 & 0 & 66626.3 & 33061.8 & $\mathbf{6 4 7 0 5 . 9}$ \\
\hline Consumer surplus & 2233330 & 2197270 & 3338890 & 2291760 & $\mathbf{1 9 4 7 ~ 1 4 0}$ \\
\hline $\begin{array}{c}\text { Transport firm's } \\
\text { profit }\end{array}$ & 588890 & 439453 & 549585 & 583571 & $\mathbf{2 7 0 3 2 9}$ \\
Platform's profit & $N A$ & $N A$ & 11100 & 8828 & $\mathbf{5 2 3 3 5 2}$ \\
\hline Welfare & 3411110 & 3076170 & 4448650 & 3411880 & $\mathbf{4 6 5 1 ~ 8 2 0}$ \\
\hline Relative efficiency & 0 & -0.0819 & 0.2537 & 0.0002 & $\mathbf{0 . 3 0 3 4}$ \\
\hline
\end{tabular}

To conclude, a MaaS with regulated supply may help consumers a bit more than even an Integrator MaaS. However, transport firms will dislike this option and will often prefer not to supply any cross-trips to the MaaS firm, making it difficult to implement. Further, regulation may be difficult and costly to implement, and there is the danger of misregulation if the marginal cost is not known or due to corruption. If we need to allow firms some profits instead of forcing them to sell at marginal costs, such regulation would be even more complex and less beneficial for consumers. So in the end such regulation does not seem very attractive, as it does little better for consumers than the best unregulated MaaS but is very sensitive to misregulation.

\section{Conclusions}

We analysed the effects of the introduction of MaaS platforms in the market for transport services on prices, demands and profits. We considered different supply chain structures with two competing transport providers and one MaaS service provider. The MaaS provider sells multimodal services from each of the two transport providers. We compared these models with a reference model in which two firms provide own-network and cross-network services without a MaaS-platform. We focus on the effects of MaaS via the market structure, and to do so ignore all other possible effectssuch as ease of use and increased demand - to make the results on the impacts via changes in competitive conditions as transparent as possible. When incorporating all possible effects of MaaS, it becomes difficult if not impossible to see the separate impacts of each.

Our first MaaS model was the System Integrator, where the transport firms set their own prices for direct services and the MaaS provider sets the cross-network prices. The MaaS provider keeps a share $\phi$ of revenue. Prices are lower than without MaaS, since the MaaS provider acts as an additional 
competitor and serial marginalisation will be eliminated. Profits for the transport firms may be a bit higher or lower. In more extreme parameter ranges, transport firms may want to stop supplying crossnetwork trips.

The second model was the Platform model, where the transport firms set all prices and the MaaS-services provider keeps a share of the revenue. In this case, profits for the transport firms may be higher or lower than with the Integrator model, but profits are lower than without MaaS. Compared to the setting without MaaS, consumers see lower prices for in-network trips but higher prices for cross-network trips. In the base calibration of our numerical model, the platform and no-MaaS settings lead to similar prices, and this remains true unless demand is very price insensitive or the platform gets a very large share of revenue. Compared to the Integrator setting, prices are higher with the Platform setting. So, the Platform model seems a decent option, as prices and profits are similar to the option without MaaS, but the Integrator model seems even better.

The third model was the Intermediary model, with the transport firms as the leaders and setting their prices first. This model reflects the retail market, where intermediaries sell products and services that are bought from manufacturers or wholesalers. This option adds extra serial marginalisationfrom the transport firms to the platform - but also adds more competition between the suppliers of final trips (now there are three). Prices are high, and profits are low. This does not seem to be a good way to introduce MaaS, and this shows the importance of optimising the way MaaS is supplied.

We finally considered a regulated case, where the transport firms are required to offer the MaaS platform their services at marginal costs. This case is great for the customers, who see much lower prices for the direct and especially cross-network transport services. The transport firms see much lower profits than with free competition, and often also lower profits than when they stop supplying cross-network services. So firms are unlikely to be willing to participate (unless they get a higher fee for cross-trips than just the marginal costs). The government also needs accurate information on the marginal cost, which may be difficult to find, leading to dangers of misregulation.

Overall, we find that intermediaries, especially when they are system integrators, will contribute to lower prices due to increased competition and less serial marginalisation. So MaaS seems beneficial even without considering the usual benefit of information provision, ease of use for consumers and increased demand for public transport. But for other market structures, in particular the Intermediary setting, prices are much higher and profits low. Hence, considering the market structure as we do is important: without considering the effects on pricing, the Intermediary model seems a logical choice for introducing MaaS.

Partly to maintain the transparency of results, our models have a number of limitations which could be dealt with in future work. 
- Most importantly, most platforms offer value-added services that we omitted for transparency. For instance, if MaaS makes public transport more attractive and thus shifts out its demand function, this would make all our MaaS settings more attractive for firms and customers.

- For all MaaS cases, we assumed away the option of cross-network trips that do not use the MaaS supplier.

- We used constant marginal costs which are normalised to zero, but for our results the important thing is that they are constant. However, in transport we often see strong economies of scale. Adding this would make results much less clear, as any change in total demand also leads to changes in average costs. We also assumed away any costs that the MaaS operator may have.

- We used linear demand functions, with strong assumptions about the parameters. We also assumed that demands and cost functions are symmetric. It seems interesting for future work to relax these simplifications.

- We assumed that firms are free to set their prices, but public transport fares are often heavily regulated.

- Quality differences between the services have not been dealt with: e.g. a higher frequency of public transport vehicles makes travel by public transport more flexible and more attractive for users. Another important "quality" element in transport is how long the trip takes, and it also relates to the value of time of users. If such quality characteristics are important, this also raises the danger of serial marginalisation in the quality setting (e.g. Czerny et al., 2016).

- We assumed linear price contracts between the transport firms and the intermediaries. Marketing research has developed a number of other contract strategies that may circumvent some of the limitations of the linear contract.

The methodology applied in this paper is rich enough to be used in assessing the contribution of MaaS-service providers and the appropriate business models. This allows ex ante analysis of the different business configurations, obviously to be followed by real-world implementation and evaluation. The results show that how the MaaS supply is organised-integrator, platform or intermediary-strongly affects the outcomes. So care is needed in setting it up. MaaS can benefit consumers by increasing competition and removing serial marginalisation, even before we consider other benefits of MaaS such as information provision and ease of use. Moreover, transport firms and MaaS firms make profits, so the setting is viable from their perspective.

\section{Acknowledgements}

The contribution of Henk Meurs is part of SCRIPTS: Smart Cities Responsive Intelligent Public Transport Systems, a SURF (Smart Urban Regions of the Future) project, an initiative funded by NWO (The Netherlands Organisation for Scientific Research), various Dutch Ministries and several private and public social partners.

\section{Declaration of interest}

The authors have no financial and personal relationships with other people or organisations that could inappropriately influence (bias) their work. 


\section{Appendix A: Detailed results for the Integrator model}

With respect to the equilibrium prices $s_{11}, s_{22}$ and $s_{12}$ and $s_{21}$ we have for this specific model:

- Equilibrium prices are decreasing in $b$. The more price sensitive demand is, the smaller markups are, both for the direct services and for the cross-network services.

- Equilibrium prices are decreasing with the substitution parameter $\gamma$ of the utility function. This implies that higher substitution between services leads to lower equilibrium prices for the direct services; competition among the different suppliers of direct and indirect services is increasing.

- Equilibrium prices for direct services are decreasing in $\varphi$; a higher share of the revenue for the platform will lead to lower prices for all services.

- The cross-network prices are higher than the prices of the direct services. This difference is decreasing in $\mathrm{b}$ and increasing in the share $\varphi$ that the platform takes.

\section{Proof of Proposition 1:}

Using the price equations in Tables $1-3$, we see that prices are strictly positive as $b>3 \cdot c>0$ must hold with substitutes, $a>0$ and $0<\phi<1$. We get the following differences in prices between the Integrator model and the free-competition cases:

$$
\begin{aligned}
& \Delta P_{11}=\Delta P_{22}=-\frac{a c}{2(2 b-5 c)} \frac{2 b+c+2 b \phi-3 c \phi}{2 b^{2}-3 b c+c^{2}(2-\phi)}<0 \\
& \Delta P_{12}=\Delta P_{21}=-\frac{a}{6(2 b-5 c)} \frac{b^{2}-c^{2}+8 c^{2} \phi}{2 b^{2}-3 b c+c^{2}(2-\phi)}<0
\end{aligned}
$$

which are clearly negative. Consequently, the Integrator model has lower prices than with free competition. Logically, consumers are better off with lower prices, and so consumer surplus is higher. Social surplus is maximised with prices equal to the marginal cost of zero, so the closer the prices are to zero the higher the welfare. Hence, the Integrator case also has the higher welfare.

Now turning to the effects of parameter ranges, we will focus on the price difference for $\Delta P_{11}$, and for the others the proofs work in the same way. We see that the first term, $\frac{a c}{2(2 b-5 c)}$, clearly increases with $c$. For the second term, the derivative is $\frac{2 b+c+2 b \phi-3 c \phi}{2 b^{2}-3 b c+c^{2}(2-\phi)}$, which again is positive when $b>3 c$. Remember that with the minus sign at the equation, $\Delta P_{11}$ becomes more negative (i.e. smaller) the larger $c$ is. Now for $b$, the derivative for the first term of $\Delta P_{11}$ is negative and the second is 
negative as well, being $-\frac{4 b^{2}+4 b c+c^{2}+\phi b(4 b-12 c)+c^{2} \phi(11-2 \phi)}{\left(2 b^{2}-3 b c-2 c^{2}+c^{2} \phi\right)^{2}}$. So $\Delta P_{11}$ becomes less negative the larger $b$ is. Finally, the derivative of $\Delta P_{11}$ towards $b$ is negative: the first term is independent of $b$, while the second term has a positive derivative of $\frac{(2 b-5 c)(b-c)(2 b+c)}{\left(2 b^{2}-3 b c-2 c^{2}+c^{2} \phi\right)^{2}}$.

Proof of Proposition 2:

Using the profit equations in Tables $1-3$, we see that the difference in transport-firm profit follows the messy equation of:

$$
\begin{gathered}
\Delta P R=\frac{-a^{2}(2 b+c)}{36(2 b-5 c)^{2}\left(2 b^{2}-3 b c+c^{2}(-2+\phi)\right)^{2}}\left[12 b^{3} c(5-33 \phi)+8 b^{4}(9 \phi-1)+2 b^{2} c^{2}(329 \phi+\right. \\
\left.\left.9 \phi^{2}-10\right)-3 b c^{3}\left(50+71 \phi+27 \phi^{2}\right)+c^{4}\left(97 \phi^{2}-62-163 \phi\right)\right] .
\end{gathered}
$$

Here, the fraction is clearly negative, but the term between brackets thereafter can be positive or negative. So profits can be lower or higher with the Integrator model than under free competition. 


\section{Appendix B: Detailed results for the Platform model}

Table 4 gives the detailed results for the Platform setting, and these will be used below in proving the propositions.

Table B.1: Price, profit and demand equilibria for the Platform model of the market structure ${ }^{17}$

\begin{tabular}{|c|c|}
\hline & Nash equilibria for prices, profits and demand for the Platform supply chain model \\
\hline \multirow{3}{*}{ Price } & $s^{*}=\frac{a(1-\phi)(3 b+c(3-2 \phi))}{-}$ \\
\hline & 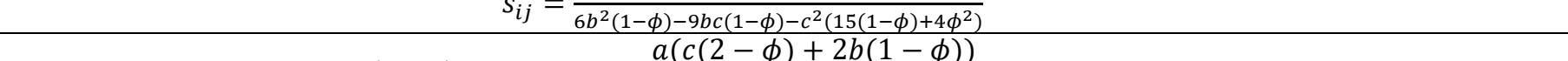 \\
\hline & $p_{i}^{*}=q_{i}^{*}=\frac{a(c(2-\phi)+2 b(1-\phi))}{6 b^{2}(1-\phi)-9 b c(1-\phi)-c^{2}\left(15-15 \phi+4 \phi^{2}\right)}$ \\
\hline $\begin{array}{c}\text { Profit } \\
\text { Transport firm }\end{array}$ & $\begin{array}{c}\pi_{t}^{*}= \\
(-1) \frac{\left(4 \varphi^{4}-28 \varphi^{3}+72 \varphi^{2}-80 \varphi+32\right) a^{2} c^{3}+\left(4 \varphi^{4}-36 \varphi^{3}+103 \varphi^{2}-118 \varphi+47\right) a^{2} b c^{2}+\left(-2 \varphi^{2}+4 \varphi-2\right) a^{2} b^{2} c+\left(8 \varphi^{3}-33 \varphi^{2}+42 \varphi-17\right) a^{2}}{\frac{1}{4}}\end{array}$ \\
\hline Profit platform & $\begin{array}{c}\pi_{p}^{*}= \\
(-1) \frac{\left(12 \varphi^{3}-44 \varphi^{2}+40 \varphi\right) a^{2} c^{3}+\left(28 \varphi^{3}-84 \varphi^{2}+64 \varphi\right) a^{2} b c^{2}+\left(8 \varphi-8 \varphi^{2}\right) a^{2} b^{2} c+\left(-16 \varphi^{3}+32 \varphi^{2}-16 \varphi\right) a^{2} b^{3}}{\left(16 \varphi^{4}-120 \varphi^{3}+345 \varphi^{2}-450 \varphi+225\right) c^{4}+\left(-72 \varphi^{3}+342 \varphi^{2}-540 \varphi+270\right) b c^{3}+\left(48 \varphi^{3}-147 \varphi^{2}+198 \varphi-99\right) b^{2} c^{2}+\left(-108 \varphi^{2}+108\right) b^{3} c+\left(36 \varphi^{2}-72 \varphi+36\right) b^{4}}\end{array}$ \\
\hline
\end{tabular}

\footnotetext{
${ }^{17}$ With respect to prices $s_{i i}$ we see that equilibrium prices decrease in $\mathrm{b}$ and increase in $\phi$. The equilibrium prices of the cross-network links $p_{i}$ and $q_{j}$ decrease with increase in $b$ and increase with increase in $\phi$, especially when $\phi$ is high.

With respect to the profits of the transport providers, we see that the profits decrease with higher price sensitivity $b$. In addition, the profits of the transport firms decrease a little with small $\phi$ but increase fast for large values for $\phi$. The former may be related to having to share the profits with the MaaS platform. The larger effects of large values of $\phi$ may be due to lower demand for crossnetwork services; these may not be attractive anymore due to high prices. For the MaaS platform, the profits decrease with increasing $b$ and become negative when the share $\phi$ gets large.

Demand for the direct services decreases with $\mathrm{b}$ and increases with $\phi$. Demand for the cross-services increases with $\mathrm{b}$ and decreases with increasing $\phi$.
} 


\section{Proof of Proposition 3:}

To start, we derive two conditions for an interior solution for the Platform model that will help. For non-negative prices $p_{i}=q_{i}$ in Table 3 , we need the denominator not to be negative: $6 b^{2}(1-\phi)-$ $9 b c(1-\phi)-c^{2}\left(15-15 \phi+4 \phi^{2}\right) \geq 0$. Using $0 \leq \phi \leq 1$ and the necessary conditions for a working demand system with imperfect substitutes $b>3 c>0$ and $a>0$, we can rewrite this to:

$$
\phi<\frac{3}{8}\left(5-\frac{2 b^{2}}{c^{2}}+\frac{3 b}{c}\right)+\frac{1}{8} \sqrt{3} \sqrt{-5+\frac{12 b^{4}}{c^{4}}-\frac{36 b^{3}}{c^{3}}-\frac{b^{2}}{c^{2}}+\frac{42 b}{c}}
$$

which puts things in terms of $\phi$ vs ratio of demand sensitivities $\frac{b}{c}$. Note that condition (B.1) is not very strict. When $b=3 c$, the $\phi$ would need to be below 0.7913 ; and, as $b$ becomes larger or $c$ smaller, the restrictions become even less strict. So in a real-world setting it will almost always hold, as it seems very extreme for the platform to keep $80 \%$ of revenue. Further, for an existing MaaS we need a positive demand for cross-network trips, $D_{i j}>0$. Using (B.1), this implies:

$$
\frac{2 b-5 c}{2 b-3 c}>\phi
$$

Again, this condition is not very strict. Using the base calibration of Section 4 , it would be $\phi<$ 0.71 ; when $b=\infty$, the condition would become $\phi<1$, and for the lowest possible $b=3 c$, it would become $\phi<1 / 3$. So only for a very low $b$ would this condition be a realistic problem.

Using the prices from Tables $1-3,0 \leq \phi \leq 1, b>3 c>0$ and $a>0$, we see that the difference in prices between the Platform and Integrator models are:

$$
\begin{aligned}
& \Delta P_{11}=\Delta P_{22}=-\frac{a(2 b+c-c \phi)}{4 b^{2}-6 b c+2 c^{2}(-2+\phi)}-\frac{a(-1+\phi)(-3 b+c(-3+2 \phi))}{6 b^{2}(-1+\phi)-9 b c(-1+\phi)+c^{2}\left(15-15 \phi+4 \phi^{2}\right)}>0 \\
& \Delta P_{12}=\Delta P_{21}=-\frac{a(2 b+c)}{4 b^{2}-6 b c+2 c^{2}(-2+\phi)}+\frac{2 a(c(-2+\phi)+2 b(-1+\phi))}{6 b^{2}(-1+\phi)-9 b c(-1+\phi)+c^{2}\left(15-15 \phi+4 \phi^{2}\right)}>0
\end{aligned}
$$

Both of these are positive when (B.1) holds, and so the Platform model has higher prices than the Intermediary model. This is not obvious in (B.3) or the price equations, but whenever the equations would suggest something else, the outcome would be a corner solution, as the Platform and possibly the Intermediary models would have negative prices following them, and this cannot be.

The differences in prices when going from free competition to the Platform model are:

$$
\begin{aligned}
& \Delta P_{11}=\Delta P_{22}=\frac{2 a c \phi(2 b(1-\phi)-c(5-3 \phi))}{(2 b-5 c)\left(6 b^{2}(-1+\phi)-9 b c(-1+\phi)+c^{2}\left(15-15 \phi+4 \phi^{2}\right)\right)}<0, \\
& \Delta P_{12}=\Delta P_{21}=-\frac{(2 / 3) a c \phi(6 b-c(15-8 \phi))}{(2 b-5 c)\left(-6 b^{2}(1-\phi)+9 b c(1-\phi)+c^{2}\left(15(1-\phi)+4 \phi^{2}\right)\right)}>0 .
\end{aligned}
$$

The denominators of these two are the same and are negative when condition (B.2) holds. The numerators are similar, and both are positive when (B.2) holds. So this implies $\Delta P_{11}=\Delta P_{22}<0$ 
and $\Delta P_{12}=\Delta P_{21}>0$. Hence, compared with free competition, the platform has lower prices for innetwork trips and higher ones for cross-network trips.

\section{Proof of Proposition 4:}

We will first look at what happens at a transport firm's profit when we go from free competition to the Platform model. The change in profit is:

$$
\Delta P R=\frac{-4 a^{2} \phi}{9(2 b-5 c)^{2}\left(6 b^{2}(-1+\phi)-9 b c(-1+\phi)+c^{2}\left(15-15 \phi+4 \phi^{2}\right)\right)^{2}} \quad\left\{\left(72 b^{5}(-1+\phi)^{2}-\right.\right.
$$

$360 b^{4} c(-1+\phi)^{2}+6 b^{3} c^{2}\left(39-100 \phi+55 \phi^{2}+6 \phi^{3}\right)-6 b^{2} c^{3}\left(-156+245 \phi-113 \phi^{2}+\right.$ $\left.\left.\left.\left.24 \phi^{3}\right)+c^{5}\left(-900+1290 \phi-615 \phi^{2}+97 \phi^{3}\right)+b c^{4}\left(-630+1284 \phi-699 \phi^{2}+113 \phi^{3}\right)\right)\right)\right\}$

Here, the fraction is clearly negative due to the minus sign. The term between curly brackets is less obvious but is positive when (B.1) holds. Accordingly, introducing MaaS via a Platform model leads to lower profits for transport firms.

Compared to the Integrator model, the Platform model can lead to higher or lower transport firm profits. The difference in profits is:

$$
\begin{aligned}
& \Delta P R=\frac{a^{2}}{4\left(2 b^{2}-3 b c-2 c^{2}+c^{2} \phi\right)^{2}\left(-6 b^{2}+9 b c+15 c^{2}+6 b^{2} \phi-9 b c \phi-15 c^{2} \phi+4 c^{2} \phi^{2}\right)^{2}}\left\{\left(16 b^{7}(-1+\phi)^{3}-\right.\right. \\
& 16 b^{6} c(-1+\phi)^{2}(-5+3 \phi)+c^{7}(-1+\phi)^{2}\left(-62+93 \phi-47 \phi^{2}+8 \phi^{3}\right)+ \\
& b c^{6}\left(-398+1083 \phi-1081 \phi^{2}+473 \phi^{3}-77 \phi^{4}\right)-8 b^{4} c^{3}\left(21-51 \phi+64 \phi^{2}-\right. \\
& \left.39 \phi^{3}+5 \phi^{4}\right)+4 b^{5} c^{2}\left(57-120 \phi+110 \phi^{2}-56 \phi^{3}+9 \phi^{4}\right)+b^{2} c^{5}(-930+ \\
& \left.2067 \phi-1565 \phi^{2}+481 \phi^{3}-61 \phi^{4}+8 \phi^{5}\right)+b^{3} c^{4}\left(-894+1833 \phi-1507 \phi^{2}+\right. \\
& \left.\left.\left.675 \phi^{3}-187 \phi^{4}+16 \phi^{5}\right)\right)\right\}
\end{aligned}
$$

The first fraction is clearly positive. It is proportional to $a^{2}$, the demand intercept only affects the overall scale of profits and profits are proportional to $a^{2}$. The denominator of the fraction is positive, as all terms are squared. The term between curly brackets is very messy and can be positive or negative, but this is not obvious. Let us replace $b$ with $r c c$, where $r=b / c>3$ is the relative size of $b$. Then the term between curly brackets becomes:

$$
\begin{aligned}
& \left(-1-3 r-2 r^{2}+\phi-r \phi+2 r^{2} \phi\right)\left(62+212 r+170 r^{2}-40 r^{3}-52 r^{4}+8 r^{5}-155 \phi-\right. \\
& 468 r \phi-271 r^{2} \phi+130 r^{3} \phi+72 r^{4} \phi-16 r^{5} \phi+140 \phi^{2}+348 r \phi^{2}+128 r^{2} \phi^{2}- \\
& 108 r^{3} \phi^{2}-20 r^{4} \phi^{2}+8 r^{5} \phi^{2}-55 \phi^{3}-100 r \phi^{3}-11 r^{2} \phi^{3}+18 r^{3} \phi^{3}+8 \phi^{4}+ \\
& \left.8 r \phi^{4}\right),
\end{aligned}
$$

which is still messy but more manageable. The first term between parentheses is always positive under our needed assumptions. The second can be positive or negative. So compared with the 
Intermediary model, with the Platform model, transport-firm profits can be higher or lower. Fig. 2 in text depicts this, and is based on the second part of the above expression. The black area is where (B.1) is violated.

Now we turn to the comparison with free competition. The profit difference is:

$$
\begin{aligned}
& \Delta P R=\frac{-4 a^{2} \phi}{\left(9(2 b-5 c)^{2}\left(6 b^{2}(-1+\phi)-9 b c(-1+\phi)+c^{2}\left(15-15 \phi+4 \phi^{2}\right)\right)^{2}\right)}\left(72 b^{5}\right. \\
& -360 b^{4} c+234 b^{3} c^{2}+936 b^{2} c^{3}-630 b c^{4}-900 c^{5}-144 b^{5} \phi \\
& +720 b^{4} c \phi-600 b^{3} c^{2} \phi-1470 b^{2} c^{3} \phi+1284 b c^{4} \phi+1290 c^{5} \phi \\
& +72 b^{5} \phi^{2}-360 b^{4} c \phi^{2}+330 b^{3} c^{2} \phi^{2}+678 b^{2} c^{3} \phi^{2}-699 b c^{4} \phi^{2} \\
& \left.-615 c^{5} \phi^{2}+36 b^{3} c^{2} \phi^{3}-144 b^{2} c^{3} \phi^{3}+113 b c^{4} \phi^{3}+97 c^{5} \phi^{3}\right)
\end{aligned}
$$

The fraction is again clearly negative, while the term between curly brackets is positive if (B.2) holds. So this implies that free competition always leads to higher firm profits than the Platform model, and this completes the proof of Proposition 4. 


\section{Appendix C: Detailed results for the Intermediary model}

From the detailed results in Table C.1 for the Intermediary model we can gather the following. The wholesale prices of the transport providers decrease with $b$. The prices for the direct services paid by the travellers decrease with $b$, and so again when demand becomes more strongly price sensitive. The crossnetwork prices also decrease with $b$. Comparing the margins of the platform, we see a positive margin for the platform provider, which is decreasing in $b$. The profits for the transport provider decrease with $b$. The platform makes some profit for larger values of $b$.

Table C.1: Price, profit and demand equilibria for the Intermediary model of the supply chain structure

\begin{tabular}{|l|c|}
\hline & $\begin{array}{c}\text { Equilibria for the Stackelberg game for transport services with the Intermediary supply chain model, with the transport firm as } \\
\text { leader }\end{array}$ \\
\hline $\begin{array}{l}\text { Equilibrium } \\
\text { prices }\end{array}$ & $p_{i}=q_{i}=(-1) \frac{a c^{4}+7 a b c^{3}+4 a b^{2} c^{2}-16 a b^{3} c+8 a b^{4}}{c^{5}+32 b c^{4}+b^{2} c^{3}-122 b^{3} c^{2}+108 b^{4} c-24 b^{5}}$ \\
\hline & $s_{i i}^{*}=(-1) \frac{4 a c^{4}+13 a b c^{3}-11 a b^{2} c^{2}-20 a b^{3} c+12 a b^{4}}{c^{5}+32 b c^{4}+b^{2} c^{3}-122 b^{3} c^{2}+108 b^{4} c-24 b^{5}}$ \\
\hline $\begin{array}{l}\text { Profit for } \\
\text { transport firm }\end{array}$ & $s_{i j}=\frac{5 a c^{4}-13 a b c^{3}-30 a b^{2} c^{2}+92 a b^{3} c-40 a b^{4}}{2 c^{5}+64 b c^{4}+2 b^{2} c^{3}-244 b^{3} c^{2}+216 b^{4} c-48 b^{5}}$ \\
\hline $\begin{array}{l}\text { Profit for } \\
\text { platform }\end{array}$ & $\pi_{t}^{*}=\frac{a^{2}\left(c^{9}+3 b c^{8}-39 b^{2} c^{7}+18 b^{3} c^{6}+368 b^{4} c^{5}-435 b^{5} c^{4}-800 b^{6} c^{3}+1784 b^{7} c^{2}-1088 b^{8} c+208 b^{9}\right)}{\left(c^{5}+32 b c^{4}+b^{2} c^{3}-122 b^{3} c^{2}+108 b^{4} c-24 b^{5}\right)^{2}}$ \\
\hline & $\begin{array}{l}\pi_{p}^{*} \\
{ }^{*}\end{array}$ \\
\hline
\end{tabular}




\section{Proof of Proposition 5:}

Let us first compare the prices with the Intermediary model with those under the Integrator model. The differences in prices are:

$$
\begin{aligned}
& \Delta P_{11}=\Delta P_{22}=\frac{a(b-c) c\left(c^{4}(15-7 \phi)-b c^{3}(-57+\phi)+8 b^{4}(5+3 \phi)+2 b^{2} c^{2}(5+11 \phi)-4 b^{3} c(17+15 \phi)\right)}{2\left(-24 b^{5}+108 b^{4} c-122 b^{3} c^{2}+b^{2} c^{3}+32 b c^{4}+c^{5}\right)\left(2 b^{2}-3 b c+c^{2}(-2+\phi)\right)}>0, \\
& \Delta P_{12}=\Delta P_{21}= \\
& \frac{a\left(32 b^{6}-112 b^{5} c+120 b^{4} c^{2}-44 b^{2} c^{4}+23 b c^{5}+11 c^{6}+40 b^{4} c^{2} \phi-92 b^{3} c^{3} \phi+30 b^{2} c^{4} \phi+13 b c^{5} \phi-5 c^{6} \phi\right)}{2\left(24 b^{5}-108 b^{4} c+122 b^{3} c^{2}-b^{2} c^{3}-32 b c^{4}-c^{5}\right)\left(2 b^{2}-3 b c-2 c^{2}+c^{2} \phi\right)}>0 .
\end{aligned}
$$

In both of these the numerator and denominator are positive when $b>3 c>0, a>0$ and $0 \leq \phi \leq 1$ hold. So the Intermediary model has higher prices than the Integrator model.

Similarly, when compared to free competition we get:

$$
\begin{aligned}
& \Delta P_{11}=\Delta P_{22}=\frac{a c\left(8 b^{4}-44 b^{3} c+82 b^{2} c^{2}-25 b c^{3}-19 c^{4}\right)}{(2 b-5 c)\left(24 b^{5}-108 b^{4} c+122 b^{3} c^{2}-b^{2} c^{3}-32 b c^{4}-c^{5}\right)}>0, \\
& \Delta P_{12}=\Delta P_{21}=\frac{a\left(48 b^{5}-288 b^{4} c+584 b^{3} c^{2}-364 b^{2} c^{3}+31 b c^{4}+83 c^{5}\right)}{6(2 b-5 c)\left(24 b^{5}-108 b^{4} c+122 b^{3} c^{2}-b^{2} c^{3}-32 b c^{4}-c^{5}\right)}>0,
\end{aligned}
$$

which again are positive, and so the Intermediary model has higher prices than free competition.

\section{Proof of Proposition 6:}

We will first compare the transport firm's profit with the Intermediary model to that with the Integrator model. The difference in profit is:

$$
\begin{gathered}
\Delta P R=\frac{a^{2}}{4 c}\left\{\frac{4\left(1+3 r-39 r^{2}+18 r^{3}+368 r^{4}-435 r^{5}-800 r^{6}+1784 r^{7}-1088 r^{8}+208 r^{9}\right)}{\left(1+32 r+r^{2}-122 r^{3}+108 r^{4}-24 r^{5}\right)^{2}}\right. \\
\left.+\frac{2+4 r^{3}(-2+\phi)-3 \phi+\phi^{2}+r\left(6-7 \phi+\phi^{2}\right)}{\left(-2-3 r+2 r^{2}+\phi\right)^{2}}\right\},
\end{gathered}
$$

with $r=b / c$ being the ratio of demand sensitivities just as for Proposition 4 and $\phi$ the revenue share for the platform in the Integrator setting. The profit difference can be negative or positive depending on $r$ and $\phi$.

Let us now compare the profit with the Intermediary model to that with free competition. The difference in profit is: 


$$
\begin{aligned}
& \Delta P R=\frac{-a^{2}}{9(2 b-5 c)^{2}\left(24 b^{5}-108 b^{4} c+122 b^{3} c^{2}-b^{2} c^{3}-32 b c^{4}-c^{5}\right)^{2}}\left\{2304 b^{11}-29952 b^{10} c+\right. \\
& 156864 b^{9} c^{2}-414720 b^{8} c^{3}+545648 b^{7} c^{4}-233056 b^{6} c^{5}-177420 b^{5} c^{6}+ \\
& \left.161696 b^{4} c^{7}+12024 b^{3} c^{8}-22465 b^{2} c^{9}-2526 b c^{10}-257 c^{11}\right\} .
\end{aligned}
$$

The first term of this is clearly negative when we consider the squares in the denominator. The second term between curly brackets can be negative or positive. This depends on the demand-parameters ratio $r=b / c$ just as for Proposition 4 . The second term is positive when:

$$
\begin{aligned}
-257-2526 r- & 22465 r^{2}+12024 r^{3}+161696 r^{4}-177420 r^{5}-233056 r^{6} \\
+ & 545648 r^{7}-414720 r^{8}+156864 r^{9}-29952 r^{10}+2304 r^{11}>0 .
\end{aligned}
$$

This proves that the profit with the intermediary can be higher or lower than with free competition

\begin{tabular}{|c|c|c|}
\hline & Demand & Profit \\
\hline $\begin{array}{l}\text { Free } \\
\text { competition }\end{array}$ & $\begin{array}{l}D_{11}: a-b * s_{11}+c^{*}\left(p_{1}+q_{2}\right)+c *\left(p_{2}+q_{1}\right)+c^{*} s_{22} \\
D_{12}: a+c * s_{11}-b *\left(p_{1}+q_{2}\right)+c *\left(p_{2}+q_{1}\right)+c * s_{22} \\
D_{21}: a+c * s_{11}+c^{*}\left(p_{1}+q_{2}\right)-b *\left(p_{2}+q_{1}\right)+c^{*} s_{22} \\
D_{22}: a+c * s_{11}+c *\left(p_{1}+q_{2}\right)+c *\left(p_{2}+q_{1}\right)-b * s_{22}\end{array}$ & $\begin{array}{l}\text { Firm 1: } D_{12} * p_{1}+D_{21} * q_{1}+s_{11} * D_{11} \\
\text { Firm 2: } D_{21} * p_{2}+D_{12} * q_{2}+s_{22} * D_{22}\end{array}$ \\
\hline $\begin{array}{l}\text { No cross- } \\
\text { network trips }\end{array}$ & $\begin{array}{l}D_{11}: a-b * s_{11}+c^{*} s_{12}+c^{*} s_{21}+c^{*} s_{22} \\
D_{22}: a+c * s_{11}+c^{*} s_{12}+c^{*} s_{21}-b^{*} s_{22}\end{array}$ & $\begin{array}{l}\text { Firm 1: } s_{11} * D_{11} \\
\text { Firm 2: } s_{22} * D_{22}\end{array}$ \\
\hline System integrator model & $\begin{array}{l}D_{11}: a-b * s_{11}+c^{*} s_{12}+c^{*} s_{2}+c^{*} s_{22} \\
D_{12}: a+c * s 11-b * s 12+c * s 21+c * s_{22} \\
D_{21}: a+c * s 11+c * s 12-b * s 21+c^{*} s_{22} \\
D_{22}: a+c * s 11+c * s 12+c * s 21-b * s_{22}\end{array}$ & $\begin{array}{l}\text { Firm 1: } D_{12} * s_{12} *(1-\varphi) / 2+D_{21} * s_{21} *(1-\varphi) / 2+s_{11} * D_{11} \\
\text { Firm 2: } D_{12} * s_{12} *(1-\varphi) / 2+D_{21} * s_{21} *(1-\varphi) / 2+s_{22} * D_{22} \\
\text { Platform: } D_{12} * s_{12} * \varphi+D_{21} * s_{21} * \varphi\end{array}$ \\
\hline $\begin{array}{l}\text { Platform model, transport } \\
\text { providers } \\
\text { setting prices }\end{array}$ & $\begin{array}{l}D_{11}: a-b * s_{11}+c^{*}\left(p_{1}+q_{2}\right)+c^{*}\left(p_{2}+q_{1}\right)+c^{*} s_{22} \\
D_{12}: a+c^{*} s_{11}-b^{*}\left(p_{1}+q_{2}\right)+c^{*}\left(p_{2}+q_{1}\right)+c^{*} s_{22} \\
D_{21}: a+c^{*} s_{11}+c^{*}\left(p_{1}+q_{2}\right)-b^{*}\left(p_{2}+q_{1}\right)+c^{*} s_{22} \\
D_{22}: a+c^{*} s_{11}+c *\left(p_{1}+q_{2}\right)+c^{*}\left(p_{2}+q_{1}\right)-b^{*} s_{22}\end{array}$ & $\begin{array}{l}\text { Firm 1: D12*p1*(1- } \varphi)+\mathrm{D} 21 * \mathrm{q} 1 *(1-\mathrm{Phi})+\mathrm{s} 11 * \mathrm{D} 11 \\
\text { Firm 2: D12*p2*(1- } \varphi)+\mathrm{D} 21 * \mathrm{q} 2 *(1-\mathrm{Phi})+\mathrm{s} 22 * \mathrm{D} 22 \\
\text { Platform: D12*(p1 + q2) *Phi + D21*(p2+q1)* } \varphi\end{array}$ \\
\hline $\begin{array}{l}\text { Intermediary model, transport } \\
\text { firms setting prices }\end{array}$ & $\begin{array}{l}D_{11}: a-b^{*} s_{11}+c^{*} s_{12}+c^{*} s_{21}+c^{*} s_{22} \\
D_{12}: a+c^{*} s_{11}-b^{*} s_{12}+c^{*} s_{21}+c^{*} s_{22} \\
D_{21}: a+c * s_{11}+c^{*} s_{12}-b^{*} s_{21}+c^{*} s_{22} \\
D_{22}: a+c^{*} s_{11}+c^{*} s_{12}+c^{*} s_{21}-b^{*} s_{22}\end{array}$ & $\begin{array}{l}\text { Firm 1: } D_{12} * p_{1}+D_{21} * q_{1}+s_{11} * D_{11} \\
\text { Firm 2: } D_{12} * p_{2}+D_{21} * q_{2}+s_{21} * D_{22} \\
\text { Platform : } D_{12} *\left(s_{11}-\left(p_{1}+q_{2}\right)\right)+D_{21} *\left(s_{22}-\left(p_{2}+q_{1}\right)\right)\end{array}$ \\
\hline
\end{tabular}
depending on $r=b / c$.

\section{Appendix D: Detailed demand and profit functions}

Table D.1: Demand for routes with links $i$ and $j(i, j=1,2)$ and profits for the supply chain models 


\section{Appendix E. Different functional forms for the demands}

To test for the effects of different functional forms of the demand function, we will redo our analyses while adding a second-order quadratic term to the own-price sensitivity. Adapting eq. 4 , the demand for using firm 1 for both legs of the trip would become the following (and similar for the other three options):

$$
D_{11}=a-b P_{11}+c\left(P_{12}+P_{21}+P_{22}\right)-b_{2} P_{11}{ }^{2}
$$

A negative $b_{2}$ implies a convex demand function, a positive $\mathrm{b}_{2}$ implies a concave one, and $b_{2}=0$ is a linear demand and is the same as our base case.

Fig. E. 1 studies the effect of changing parameter $b_{2}$ on the prices $P_{11}=P_{22}$ and $P_{12}=\mathrm{P}_{21}$ and the transport firm profits $P R_{I}=P R_{2}$. It does so for our best two MaaS settings and compares their outcome to that in the free-competition setting without MaaS by giving the percentage differences. We see that the Integrator model leads to lower prices and profits than free competition, while the Platform model leads to about the same outcome as free competition. Changing the shape of the demand function does not alter our qualitative main results, although there are quantitative effects. Interestingly, the effect of making the demand convex (negative $b_{2}$ ) is stronger than making it concave. Also, if $b_{2}$ gets negative enough, then the Platform model gives a slightly larger profit than free competition, while in our base case it leads to a slightly lower one. But of course this is in line with our results, since Proposition 6 and the other sensitivity analyses already concluded that the profit can be higher or lower depending on the parameters.

To conclude, changing the shape of our demand function does not seem to change the main results of our numerical model. Although this is only a limited sensitivity check, this suggests that our overall results should be robust to the choice of type of demand function.

Fig. E.1: Effect of changing parameter $b_{2}$ (which affects the shape of the demand function) of the percent difference in prices and profits between our MaaS settings and free competition (without MaaS setting).

(a) Platform vs free competition

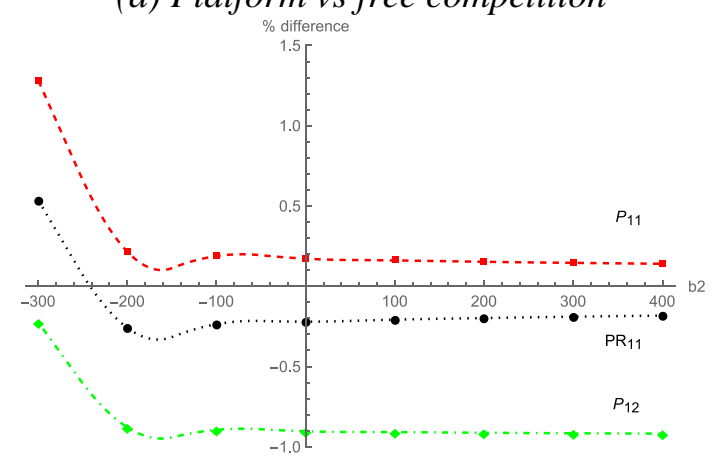

(b) Integrator vs free competition

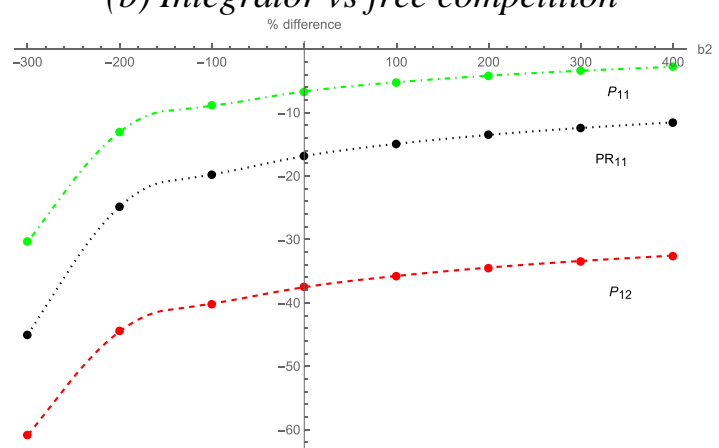

Note: Changing $\mathrm{b}_{2}$ changes the shape of the demand function in E.1. A negative $b_{2}$ implies a convex demand function, a positive $b_{2}$ implies a concave one, and $b_{2}=0$ is a linear demand and is the same as our base case. 


\section{References}

Brueckner, J.K., 2001. The economics of international codesharing: an analysis of airline alliances. International Journal of Industrial Organization 19(10), 1475-1498.

Choi, S.C., 1991. Price competition in a channel structure with a common retailer. Marketing Science 10(4), 271296.

Clark, D.J., Jørgensen, F., Mathisen, T.A., 2014. Competition in complementary transport services. Transportation Research Part B: Methodological 60, 146-159.

Czerny, A.I., van den Berg, V.A.C., Verhoef, E.T., 2016. Carrier collaboration with endogenous fleets and load factors when networks are complementary. Transportation Research Part B: Methodological 94, 285-297.

D’Alfonso, T., Jiang, C., Bracaglia, V., 2016. Air transport and high-speed rail competition: environmental implications and mitigation strategies. Transportation Research Part A: Policy and Practice 92, 261-276.

Di, X., Ban, X. J., 2019. A unified equilibrium framework of new shared mobility systems. Transportation Research Part B: Methodological 129, 50-78.

Djavadian, S., Chow, J.Y., 2017. An agent-based day-to-day adjustment process for modeling 'mobility as a service' with a two-sided flexible transport market. Transportation Research Part B: Methodological 104, 36-57.

Economides, N., Salop, S.C., 1992. Competition and integration among complements, and network market structure. Journal of Industrial Economics 40(1), 105-123.

Ecorys, 2015. Effecten toetreding nieuwe mobiliteitskaartaanbieders op bestaande ov-concessies (Effects of entry of new mobility card providers on existing public transport concessions, in Dutch). Report prepared for the Dutch Ministery of Transport and Waterworks. Rotterdam.

Jittrapirom, P., Caiati, V., Feneri, A.M., Ebrahimigharehbaghi, S., Alonso-Gonzalez, M.J., Narayan, J., 2017. Mobility as a service: a critical review of definitions, assessments of schemes, and key challenges. Urban Planning, 2, 13-25.

Kamargianni, M., Li, W., Matyas, M., \& Schäfer, A. (2016). A critical review of new mobility services for urban transport. Transportation Research Procedia, 14, 3294-3303.

Kaspi, M., Raviv, T., Tzur, M., 2014. Parking reservation policies in one-way vehicle sharing systems. Transportation Research Part B: Methodological 62, 35-50.

Ke, J., Yang, H., Li, X., Wang, H., Ye, J., 2020. Pricing and equilibrium in on-demand ride-pooling markets. Transportation Research Part B: Methodological, 139, 411-431.

Lin, M.H., 2004. Strategic airline alliances and endogenous Stackelberg equilibria. Transportation Research Part E: Logistics and Transportation Review, 40(5), 357-384

Ma, R., Zhang, H.M., 2017. The morning commute problem with ridesharing and dynamic parking charges, Transportation Research Part B: Methodological 106, 345-374.

Mantin, B., 2012. Airport complementarity: private vs. government ownership and welfare gravitation. Transportation Research Part B: Methodological 46(3), 381-388.

Meurs, H, Sharmeen, F., Marchau, V., van der Heijden, R., 2020. Organizing integrated services in mobility-asa-service systems: principles of alliance formation applied to a MaaS-pilot in The Netherlands. Transportation Research Part A: Policy and Practice 131, 178-195.

Pandey, V., Monteil, J., Gambella, C., Simonetto, A., 2019. On the needs for MaaS platforms to handle competition in ridesharing mobility. Transportation Research Part C: Emerging Technologies 108, 269-288.

Pantelidis, T.P., Chow, J.Y., Rasulkhani, S., 2020. A many-to-many assignment game and stable outcome algorithm to evaluate collaborative mobility-as-a-service platforms. Transportation Research Part B: Methodological 140, 79-100.

Park, S.Y., Keh, H.T., 2003. Modelling hybrid distribution channels: a game-theoretic analysis. Journal of Retailing and Consumer Services 10(3), 155-167.

Pöllänen, J., 2020. Whim, how to make yourself ready for mobility as a service? https://www.maasmarket.com/sites/default/files/JOANNA\%20POLLANEN.pdf. Accessed 20 May 2020.

Polydoropoulou, A., Pagoni, I., Tsirimpa, A., Roumboutsos, A., Kamargianni, M., Tsouros, I., 2020. Prototype business models for mobility-as-a-service. Transportation Research Part A: Policy and Practice 131, 149-162.

Rasulkhani, S., Chow, J.Y., 2019. Route-cost-assignment with joint user and operator behavior as a many-toone stable matching assignment game. Transportation Research Part B: Methodological 124, 60-81.

Silva, H.E., Verhoef, E.T., 2013. Optimal pricing of flights and passengers at congested airports and the efficiency of atomistic charges. Journal of Public Economics 106, 1-13.

Simoni, M.D., Kockelman, K.M., Gurumurthy, K.M., Bischoff, J., 2019. Congestion pricing in a world of selfdriving vehicles: an analysis of different strategies in alternative future scenarios. Transportation Research Part C: Emerging Technologies 98, 167-185.

Singh, N., Vives, X., 1984. Price and quantity competition in a differentiated duopoly. The Rand Journal of Economics 15(4), 546-554. 
Tan, B.Q., Xu, S.X., Zhong, R., Cheng, M., Kang, K., 2019. Sequential auction based parking space sharing and pricing mechanism in the era of sharing economy. Industrial Management \& Data Systems 119(8), 1734-1747.

Van de Velde, D.M., 2005. Co-ordination, integration and transport regulation. In Button, K.J. and Hensher, D.A. (Eds) Handbook of Transport Strategy, Policy and Institutions. Elsevier, Oxford. 115-134.

van den Berg, V.A.C., 2013. Serial private infrastructures. Transportation Research Part B: Methodological 56, $186-202$

van den Berg, V.A.C, Verhoef, E.T., 2016. Autonomous cars and dynamic bottleneck congestion: the effects on capacity, value of time and preference heterogeneity. Transportation Research Part B: Methodological 94, 43-60.

Verhoef, E.T., 2008. Private roads: auctions and competition in networks. Journal of Transport Economics and Policy 42(3), 463-493.

Verhoef, E.T., Emmerink, R.H., Nijkamp, P., Rietveld, P., 1996. Information provision, flat and fine congestion tolling and the efficiency of road usage. Regional Science and Urban Economics 26(5), 505-529.

Vij, A., Ryan, S., Sampson, S., Harris, S., 2020. Consumer preferences for mobility-as-a-service (MaaS) in Australia. Transportation Research Part C: Emerging Technologies 117, 102699.

Zhang, R., Liu, B., Wang, W., 2012. Pricing decisions in a dual channels system with different power structures. Economic Modelling 29(2), 523-533. 